\title{
Assessment of the 3430 Building Filtered Exhaust Stack Sampling Probe Location
}

\author{
JA Glissmeyer \\ JE Flaherty
}

July 2010

Pacific Northwest

NATIONAL LABORATORY

Proudly Operated by Battelle Since 1965 


\section{DISCLAIMER}

This report was prepared as an account of work sponsored by an agency of the United States Government. Neither the United States Government nor any agency thereof, nor Battelle Memorial Institute, nor any of their employees, makes any warranty, express or implied, or assumes any legal liability or responsibility for the accuracy, completeness, or usefulness of any information, apparatus, product, or process disclosed, or represents that its use would not infringe privately owned rights. Reference herein to any specific commercial product, process, or service by trade name, trademark, manufacturer, or otherwise does not necessarily constitute or imply its endorsement, recommendation, or favoring by the United States Government or any agency thereof, or Battelle Memorial Institute. The views and opinions of authors expressed herein do not necessarily state or reflect those of the United States Government or any agency thereof.

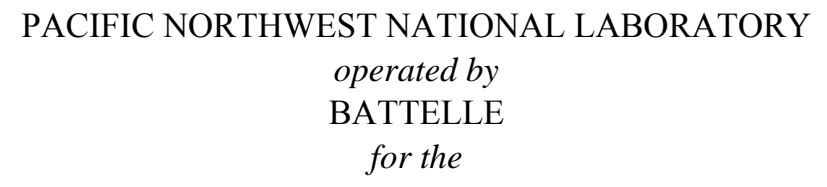

UNITED STATES DEPARTMENT OF ENERGY under Contract DE-ACO5-76RL01830

Printed in the United States of America

Available to DOE and DOE contractors from the Office of Scientific and Technical Information, P.O. Box 62, Oak Ridge, TN 37831-0062; ph: (865) 576-8401 fax: (865) 5765728

email: reports@adonis.osti.gov

Available to the public from the National Technical Information Service, U.S. Department of Commerce, 5285 Port Royal Rd., Springfield, VA 22161 ph: (800) 553-6847 fax: (703) 605-6900 email: orders@nits.fedworld.gov online ordering: http://www.ntis.gov/ordering.htm 
PNNL-19262, Rev. 1

RPT-STMON-002, Rev. 1

\title{
Assessment of the 3430 Building Filtered Exhaust Stack Sampling Probe Location
}

\author{
JA Glissmeyer \\ JE Flaherty
}

July 2010

Prepared for

the U.S. Department of Energy

under Contract DE-AC05-76RL01830

Pacific Northwest National Laboratory

Richland, Washington 99352 
Completeness of Testing

This report describes the results of work and testing specified by test plan TP-STMON001. The work and any associated testing followed the quality assurance requirements outlined in the test specification/plan. The descriptions provided in this test report are an accurate account of both the conduct of the work and the data collected. Test plan results are reported. Also reported are any unusual or anomalous occurrences that are different from expected results. The test results and this report have been reviewed and verified.

Approved:

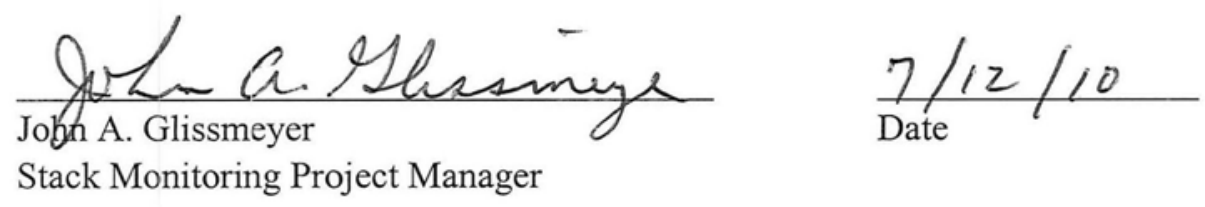




\section{Summary}

Pacific Northwest National Laboratory performed a demonstration to determine the acceptable location in which to place an air sampling probe for emissions monitoring for radionuclides in the exhaust air discharge from the new 3430 Building Filtered Exhaust Stack. The method was to adopt the results of a previously performed test series for a system of similar configuration, followed by a partial test on the actual system to verify the applicability of previously performed tests. The qualification criteria included 1) a uniform air velocity, 2) an average flow angle that does not deviate from the axis of the duct by more than $20^{\circ}, 3$ ) a uniform concentration of tracer gases, and 4) a uniform concentration of tracer particles.

Section 1 provides background information for the demonstration, and Section 2 describes the test strategy, including the criteria for the applicability of model results and the test matrix. Section 3 describes the flow -angle test and the velocity uniformity test, Section 4 provides the test results, and Section 5 provides the conclusions. Appendix A includes the test data sheets, and Appendix B gives applicable qualification results from the previously tested model stack.

The data from the previously tested and similarly designed stack was demonstrated to be applicable to the current design for the 3430 Building Filtered Exhaust Stack. The 3430 stack was tested in both January and May of 2010 to document the results of several changes that were made to the exhaust system after the January tests. The 3430 stack meets the qualification criteria given in the American National Standards Institute/Health Physics Society N13.1-1999 standard. Changes to the system configuration or operations outside of the bounds of this report (e.g., exhaust velocity increases, relocation of sample probe) will require retesting/reevaluation to determine compliancewith the requirements. 



\section{Acronyms}

acfm

$\mathrm{AD}$

ANSI

ASME

CFR

COV

D

DIA

DOE

DV

EPA

FA

HDI

HPS

NQA

PNNL

QA

R\&D

scfm

STMON

VT actual cubic feet per minute

aerodynamic diameter

American National Standards Institute

America Society of Mechanical Engineers

Code of Federal Regulations

coefficient of variance

duct diameter

number of duct diameters, distance divided by duct diameter

U.S. Department of Energy

product of duct diameter and mean air velocity

U.S. Environmental Protection Agency

flow-angle test run

"How Do I...?"

Health Physics Society

Nuclear Quality Assurance

Pacific Northwest National Laboratory

quality assurance

research and development

standard cubic feet per minute

Stack Monitoring Project

velocity uniformity test run 



\section{Contents}

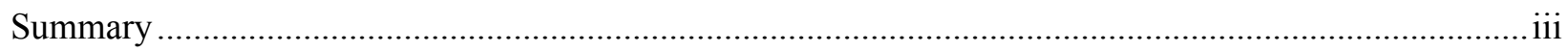

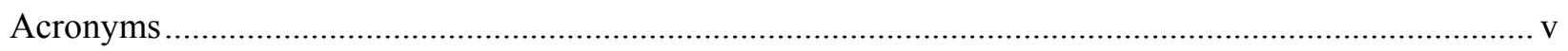

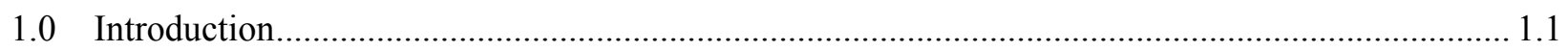

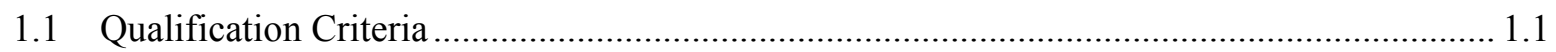

1.23430 Building Filtered Exhaust Stack Configuration ............................................................ 1.3

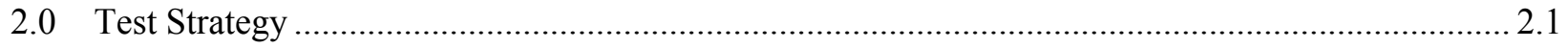

2.1 Criteria for Applicability of Model Results ................................................................. 2.1

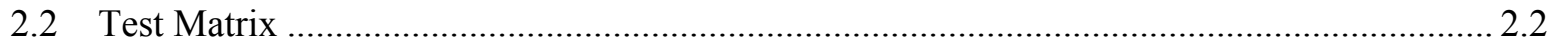

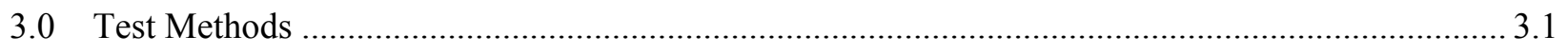

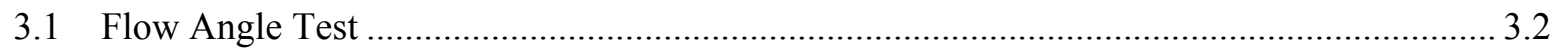

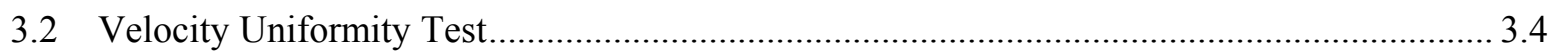

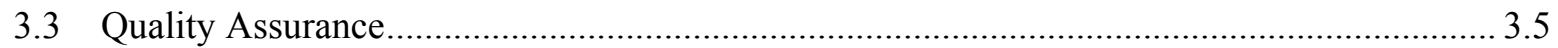

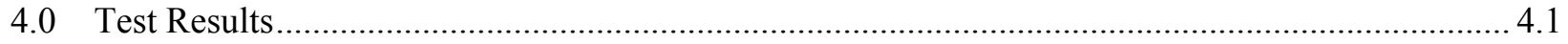

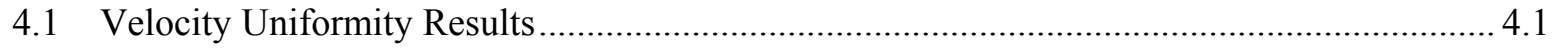

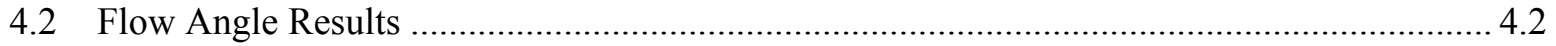

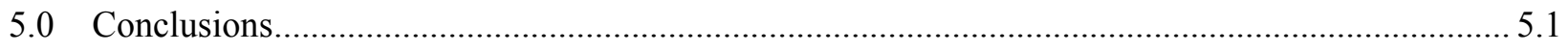

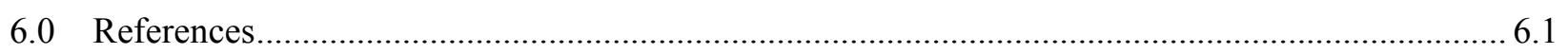

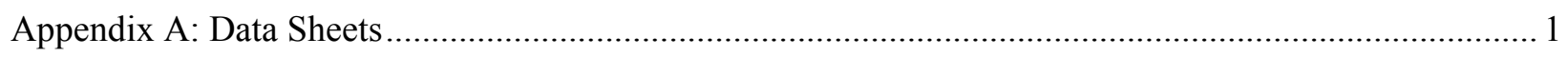

Appendix B: Applicable Qualification Results from the Model Stack ................................................... 1

\section{Figures}

Figure 1.1. Plan View of 3430 Building Filtered Exhaust Stack ....................................................... 1.4

Figure 1.2. Scale Model Tested by Glissmeyer and Droppo (2007) .................................................... 1.5

Figure 3.1. Layout of Test Ports and Other Duct Features ................................................................. 3.1

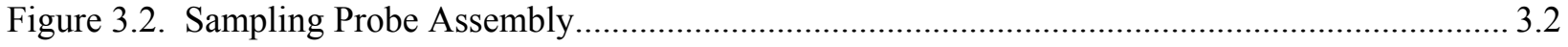

Figure 3.3. Flow Angle Indicator and Pitot Tube Installed................................................................ 3.3

Figure 3.4. Slant Tube Manometer on Inspection Hatch Cover ........................................................... 3.4

Figure 3.5. Electronic Manometer Connected to Pitot Tube .................................................................. 3.5 


\section{Tables}

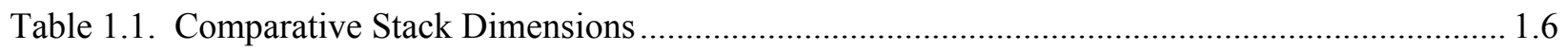

Table 2.1. $\quad$ List of HV-C2 Velocity Uniformity Test Results with Dampers Installed................. 2.1

Table 2.2. Calculation of Acceptable Ranges of Diameter $\times$ Velocity Products and Reynolds Number 2.2

Table 2.3. Minimum Test Runs for 3430 Building Qualification....................................................... 2.2

Table 4.1. Test Port Depth Measurements .......................................................................................... 4.1

Table 4.2. 3430 Building Filtered Exhaust Stack Velocity Uniformity Test Runs................................. 4.2

Table 4.3. 3430 Building Filtered Exhaust Stack Flow Angle Test Runs ............................................. 4.2 


\subsection{Introduction}

Pacific Northwest National Laboratory (PNNL) determined that emissions monitoring must be conducted for radionuclides in the exhaust air discharge from the new 3430 Building. The performance of the air monitoring system must conform to the applicable federal regulations (Title 40 of the Code of Federal Rgulations Part 61 [40 CFR 61], Subpart H). This regulation requires that a sampling probe be located in the 3430 Building Filtered Exhaust Stack according to the criteria of the ANSI/HPS ${ }^{\mathrm{a}}$ N13.11999, Sampling and Monitoring Releases of Airborne Radioactive Substances from the Stack and Ducts of Nuclear Facilities. This standard requires that a series of tests be performed to demonstrate the acceptability of the location of the air sampling probe in the system. The test series includes measurement of the flow angle, velocity uniformity, gas tracer uniformity, and particle tracer uniformity as measured in the stack cross section at the sampling probe nozzle location.

A facility may choose to perform the demonstration using one of the following three approaches:

1. Perform the full test series on the actual exhaust system.

2. Perform the full test series on a scale model of the exhaust system, followed by a partial test of the actual exhaust system to verify the validity of the model results.

3. Adopt the results of a previously performed test series for a system of similar configuration, followed by a partial test of the actual system to verify the applicability of the previously performed tests.

The third approach was selected to to evaluate the acceptability of the location of the air sampling probe in 3430 Building filtered exhaust stack to monitor discharged air for radionuclides. Consequently, a limited series of tests was performed on the actual exhaust system using the criteria for qualifying the location of a stack air monitoring probe and the configuration of the 3430 Building filtered exhaust stack, as described below. Then the results were compared to those of the previously tested system.

This report describes the tests performed on the actual system and also presents the results from the previously tested system that serves as the basis for compliance with the standard as it relates to the sampling probe location.

The tests conducted by PNNL during January and May 2010 on the 3430 Building filtered air exhaust system are described in this report. The test results indicate that the proposed air sampling location meets the criteria of the standard.

\subsection{Qualification Criteria}

The qualification criteria for a stack air monitoring probe location are taken from ANSI/HPS N13.11999 and are paraphrased as follows:

1. Uniform Air Velocity - It is important that the gas velocity across the stack cross-section where the sample is extracted be fairly uniform. Consequently, the velocity is measured at several points in the stack at the position of the sampling nozzle. The uniformity is expressed as the variability of the

\footnotetext{
${ }^{a}$ American National Standards Institute delegates the writing, publication and maintenance of this standard to the Health Physics Society, McLean, Virginia.
} 
measurements about the mean. This is expressed using the coefficient of variation $(\mathrm{COV}){ }^{(\mathrm{a})}$ which is the standard deviation divided by the mean and expressed as a percentage. The lower the COV value, the more uniform the velocity. The acceptance criterion is that the COV of the air velocity must be $\leq 20 \%$ across the sampling plane.

2. Angular Flow - Sampling nozzles are typically aligned with the axis of the stack. If the air travels up the stack in cyclonic fashion, the air velocity vector approaching a sampling nozzle could be sufficiently misaligned with the nozzle to impair the extraction of particles. Consequently, the flow angle is measured in the duct at the proposed location of the sampling probe. The average airvelocity angle must not deviate from the axis of the duct by more than $20^{\circ}$.

3. Uniform Concentration of Tracer Gases - A uniform contaminant concentration in the sampling plane enables the extraction of samples that represent the true concentration within the duct. The uniformity of the concentration is first tested using a tracer gas to represent gaseous effluents. The fan is a good mixer, so injecting the tracer downstream of the fan provides worst-case results. The acceptance criteria are that 1) the COV of the measured tracer gas concentration is $\leq 20 \%$ across the sampling location and 2) at no point in the sampling location does the concentration vary from the mean by $>30 \%$.

4. Uniform Concentration of Tracer Particles - The second set of tests addressing contaminantconcentration uniformity at the sampling position uses tracer particles large enough to exhibit inertial effects. Tracer particles of $10-\mu \mathrm{m}\left(10^{-6} \mathrm{~m}\right)$ aerodynamic diameter (AD) are used by default unless it is known that larger contaminant particles will be present in the airstream. The acceptance criterion is that the COV of particle concentration is $\leq 20 \%$ across the sampling location.

It was determined that compliance with these criteria was already demonstrated for a similar stack configuration by testing a scale model as reported by Glissmeyer and Droppo (2007).

To be able to apply the results of the scale model tests, Section 5.2.2.2 of the ANSI/HPS N13.1-1999 standard defines additional criteria for applying the results as a substitute for the actual 3430 Building Filtered Exhaust Stack.

- The scale model and its sampling location must be geometrically similar to the actual 3430 Building Filtered Exhaust Stack.

- The product of the duct diameter and the mean velocity (DV) for the scale model must be within a factor of six of the DV for the actual 3430 Building Filtered Exhaust Stack.

- The Reynolds number for the actual and model stacks must be $>10,000$.

The scale-model results are considered valid if the following are shown by testing on the actual stacks:

- The velocity profile in the actual 3430 Building Filtered Exhaust Stack meets the uniformity criterion.

- The velocity uniformity COV values for the actual and model stacks agree within 5\% COV.

- The flow angle criterion (with a mean value less than or equal to $20^{\circ}$ ) is met.

(a) Coefficient of variation is considered "dated" terminology. The modern terminology is percent relative standard deviation. However, because the standard uses the older terminology, it will likewise be used here. 


\subsection{Building Filtered Exhaust Stack Configuration}

Figure 1.1 shows a crude plan view of the 3430 Building Filtered Exhaust Stack on the roof of the 3430 Building. Figure 1.2 shows the scale model stack (designated HV-C2) tested by Glissmeyer and Droppo (2007). 


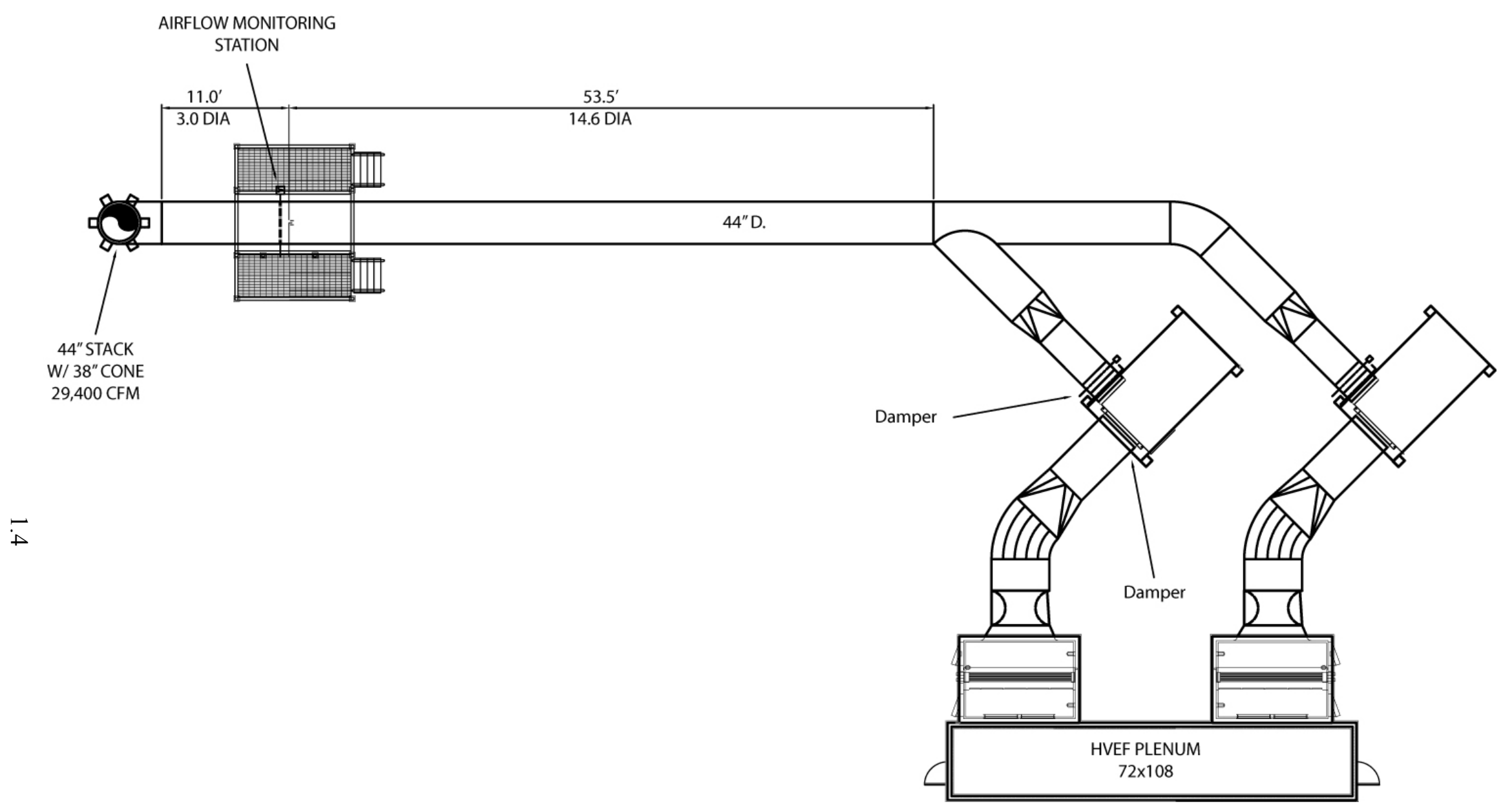

Figure 1.1. Plan View of 3430 Building Filtered Exhaust Stack 


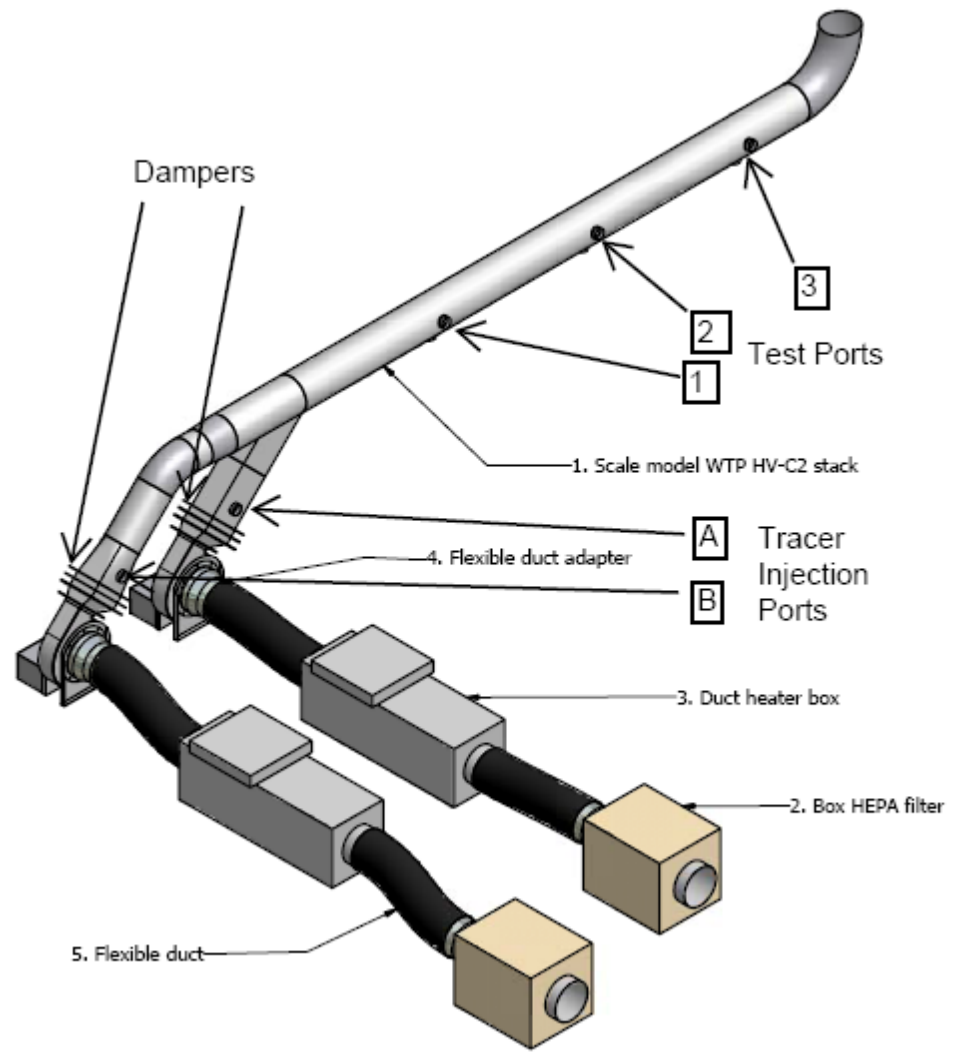

Figure 1.2. Scale Model Tested by Glissmeyer and Droppo (2007)

The difference between the two designs is that the model stack (except for the bend upwards at the discharge end) is rotated $90^{\circ}$ around its long axis so that the air from the fans enters the straight section from the side rather than from the bottom. This should have no effect on the uniformity of tracers and the air velocity uniformity and flow angles. The model stack was tested with one and both fans operating, which covers the possible operating modes.

Table 1.1 lists key dimensional and flow parameters for both the model stack and the 3430 Building Filtered Exhaust Stack. During the first set of tests, which were conducted in January 2010, the discharge diameter was 38 in. However, after these tests were conducted, additional fume hoods were incorporated into the exhaust system. With the increased flow through the system, the stack exit cone was removed so the discharge diameter during the May 2010 testing was 44 in. 
Table 1.1. Comparative Stack Dimensions

\begin{tabular}{|c|c|c|}
\hline Operating Parameters & Model & 3430 Building \\
\hline Duct diameter at sampling probe & $12 \mathrm{in.}$ & 43.75 in. \\
\hline $\begin{array}{l}\text { Number of duct diameters }{ }^{(a)} \text { from upstream duct } \\
\text { junction to sampling probe or test ports }\end{array}$ & $\begin{array}{l}\text { Port } 1-4.45 \\
\text { Port } 2-9.47 \\
\text { Port } 3-14.5\end{array}$ & 14.6 \\
\hline $\begin{array}{l}\text { Number of duct diameters from sampling probe or test } \\
\text { ports to downstream bend }\end{array}$ & Port $3-2.25$ & 3 \\
\hline Discharge diameter & $12 \mathrm{in.}$ & 38 in. / 44 in. \\
\hline Number of operating fans & 1 and 2 & 2 \\
\hline Total available fans & 2 & 2 \\
\hline
\end{tabular}




\subsection{Test Strategy}

The criteria for the applicability of model results and the matrix of tests underlying the testing strategy are described in the following sections.

\subsection{Criteria for Applicability of Model Results}

The velocity uniformity test results from the model stack are a factor in the formulation of one of the criteria for the applicability of the model results to any other stack. Table 2.1 lists the results from the velocity uniformity tests performed on the model using Test Ports 2 and 3 for both one and two operating fans. The average velocity uniformity ( $\% \mathrm{COV}$ ) results were $4.8 \% \mathrm{COV}$ and $4.9 \% \mathrm{COV}$ for one and two operating fans, respectively. The most applicable test results for comparison with the 3430 Building exhaust system are the scale model results from Test Port 3 when both fans were running. The average velocity uniformity for these conditions was $4.7 \% \mathrm{COV}$. Therefore, the acceptance range for velocity uniformity results for the 3430 Building Filtered Exhaust Stack is $0 \% \mathrm{COV}$ to $9.7 \% \mathrm{COV}$ afor the results from the HV-C2 scale model to be considered applicable.

Table 2.1. List of HV-C2 Velocity Uniformity Test Results with Dampers Installed (from Glissmeyer and Droppo 2007)

\begin{tabular}{|c|c|c|c|c|c|c|c|}
\hline $\begin{array}{l}\text { Test } \\
\text { Port }\end{array}$ & $\begin{array}{c}\text { Operating } \\
\text { Fans }\end{array}$ & $\begin{array}{l}\text { Run } \\
\text { No. }\end{array}$ & $\begin{array}{c}\text { Control } \\
\text { Damper } \\
\text { Setting } \\
\text { (degrees) }\end{array}$ & $\begin{array}{c}\text { Back Flow } \\
\text { Damper Setting } \\
\text { (degrees) }\end{array}$ & $\begin{array}{c}\text { Flowrate } \\
\text { cfm }\end{array}$ & $\begin{array}{c}\text { Velocity } \\
\text { fpm }\end{array}$ & $\% \mathrm{COV}$ \\
\hline 2 & $\overline{\mathrm{A}}$ & VT-16 & 90 & 70 & 973 & 1239 & 3.6 \\
\hline 2 & B & VT-19 & 90 & 70 & 977 & 1244 & 6 \\
\hline 3 & A & VT-17 & 90 & 70 & 1002 & 1276 & 3.4 \\
\hline \multirow[t]{2}{*}{3} & B & VT-18 & 90 & 70 & 959 & 1221 & 6 \\
\hline & & & & Average & 977.8 & 1245.0 & 4.8 \\
\hline 2 & $A \& B$ & VT-13 & 90 & 70 & 2094 & 2666 & 6.1 \\
\hline 2 & $A \& B$ & VT-23 & 90 & 70 & 2132 & 2715 & 5.1 \\
\hline 2 & $A \& B$ & VT-24 & 90 & 70 & 2126 & 2706 & 4.4 \\
\hline 3 & $A \& B$ & VT-14 & 90 & 70 & 2117 & 2696 & 4.4 \\
\hline 3 & $A \& B$ & VT-21 & 90 & 70 & 2136 & 2720 & 5.1 \\
\hline \multirow[t]{2}{*}{3} & $A \& B$ & VT-22 & 90 & 70 & 2180 & 2775 & 4.5 \\
\hline & & & & Average & 2130.8 & 2713.0 & 4.9 \\
\hline
\end{tabular}

Table 2.2 shows calculations of the acceptable range of the diameter $\times$ velocity criterion that also determines the applicability of the scale-model results to the actual stacks. The product of duct diameter times air velocity during both tests $(\mathrm{DV}=113,750$ / $\mathrm{DV}=144,375)$ was within the acceptable factor of six of the scale model's DV product $(32,556 \times 6=195,336)$ for two operating fans. Table 2.2 also includes the Reynolds number for the scale tests and the building stack tests. In all cases, the Reynolds numbers are greater than 10,000, which is another criterion for applying the scale model results to the building stack

a $4.7 \% \pm 5.0 \%=0 \%-9.7 \%$ (considering only positive values). 
Table 2.2. Calculation of Acceptable Ranges of Diameter $\times$ Velocity Products and Reynolds Number

\begin{tabular}{ccccccc}
\hline Stack & $\begin{array}{c}\text { Diameter } \\
\text { (in) }\end{array}$ & Configuration & $\begin{array}{c}\text { Mean. velocity } \\
(\mathrm{fpm})\end{array}$ & $\begin{array}{c}\text { Product DV, } \\
\text { in } \times \mathrm{fpm}\end{array}$ & $\begin{array}{c}\text { Maximum 6 } \\
\times(\mathrm{D} \times \mathrm{V})\end{array}$ & $\begin{array}{c}\text { Reynolds } \\
\text { Number }\end{array}$ \\
\hline Model & 12 & One fan & 1245 & 14,940 & 89,640 & $1.3 \mathrm{E}+05$ \\
Model & 12 & Two fans & 2713 & 32,556 & 195,336 & $2.8 \mathrm{E}+05$ \\
3430-Jan & 43.75 & Two Fans & 2600 & 113,750 & & $9.8 \mathrm{E}+05$ \\
3430-May & 43.75 & Two Fans & 3300 & 144,375 & & $1.3 \mathrm{E}+06$ \\
\hline
\end{tabular}

\subsection{Test Matrix}

Table 2.3 lists the minimum matrix of tests needed for the 3430 Building Filtered Exhaust Stack. Also included in the list are the optional tests that may be required if the applicable criteria for velocity uniformity and diameter/velocity product were not met as presented above.

Table 2.3. Minimum Test Runs for 3430 Building Qualification

\begin{tabular}{|c|c|c|c|c|c|c|c|}
\hline \multicolumn{4}{|c|}{ Test Configuration } & \multicolumn{4}{|c|}{ Estimated Number of Test Runs } \\
\hline Fans & $\#$ & $\begin{array}{l}\text { Injection } \\
\text { Port }\end{array}$ & Test Port & Flow Angle & Velocity & $\begin{array}{l}\text { Gas Tracer } \\
\text { (optional) }^{(a)}\end{array}$ & $\begin{array}{c}\text { Particle } \\
\text { Tracer } \\
\text { (optional) }\end{array}$ \\
\hline $\begin{array}{l}\text { Maximum } \\
\text { flowrate }\end{array}$ & 1 & Junction & At Probe & 2 & 2 & 7 & 2 \\
\hline $\begin{array}{l}\text { Minimum } \\
\text { flowrate }\end{array}$ & 2 & Junction & At Probe & 1 & 1 & 1 & 1 \\
\hline \multicolumn{4}{|c|}{ Total } & 3 & 3 & 8 & 3 \\
\hline \multicolumn{4}{|c|}{ Grand Total } & \multicolumn{4}{|c|}{17} \\
\hline
\end{tabular}

(a) Five of the seven runs involve injecting the tracer gas in the four corners and center of the cross section at the injection location. The two additional runs are replicates of the test with the worst-case result. 


\subsection{Test Methods}

The test methods for the flow angle and velocity uniformity are outlined below. Tracer tests are not currently planned. Figure 3.1 shows the layout of the duct in the location of the air sampling probe and the test ports used in the test.

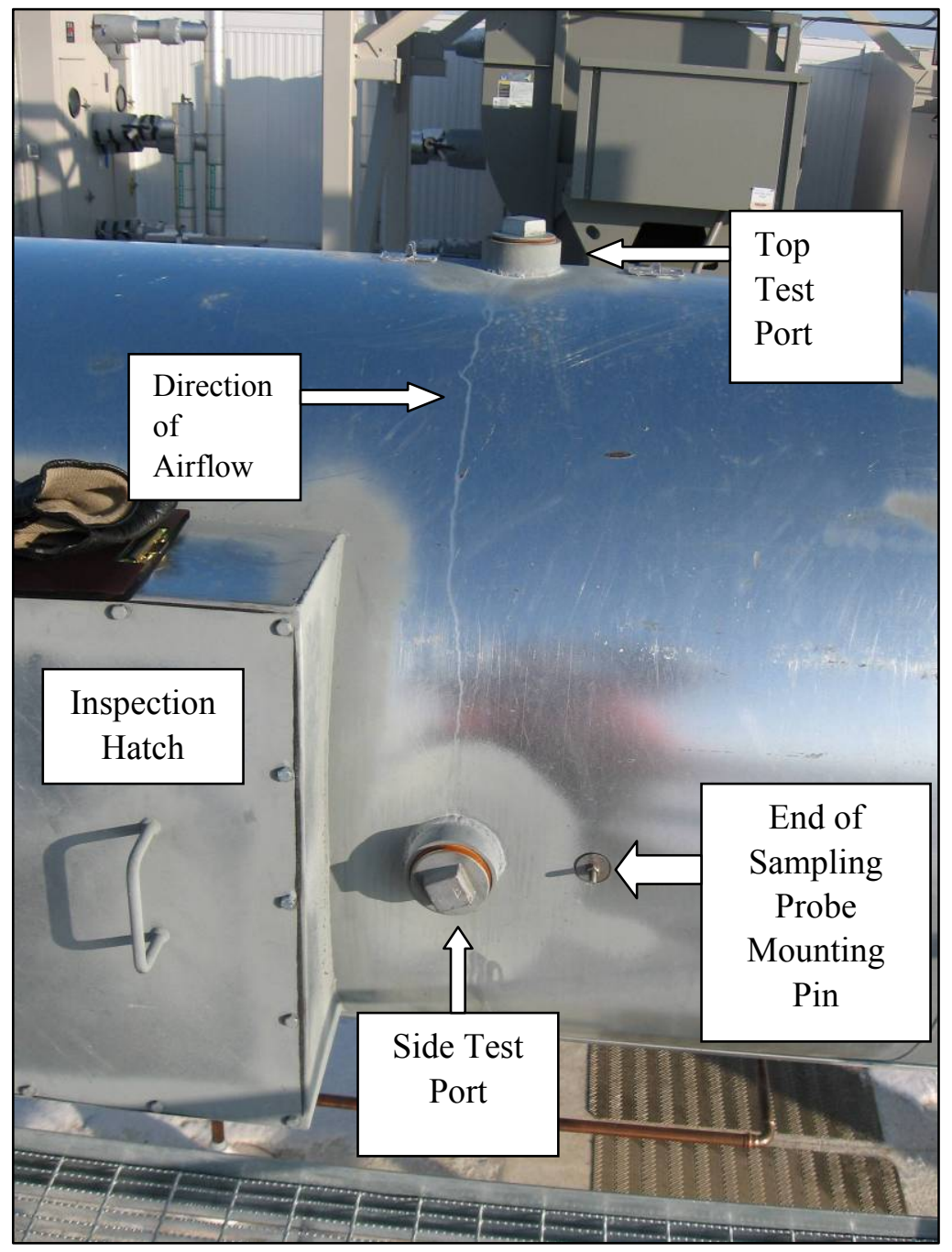

Figure 3.1. Layout of Test Ports and Other Duct Features

Figure 3.2 shows the inside of the duct looking downstream (with inspection hatch removed). A shrouded nozzle and flow sensor are part of the sample probe assembly. 


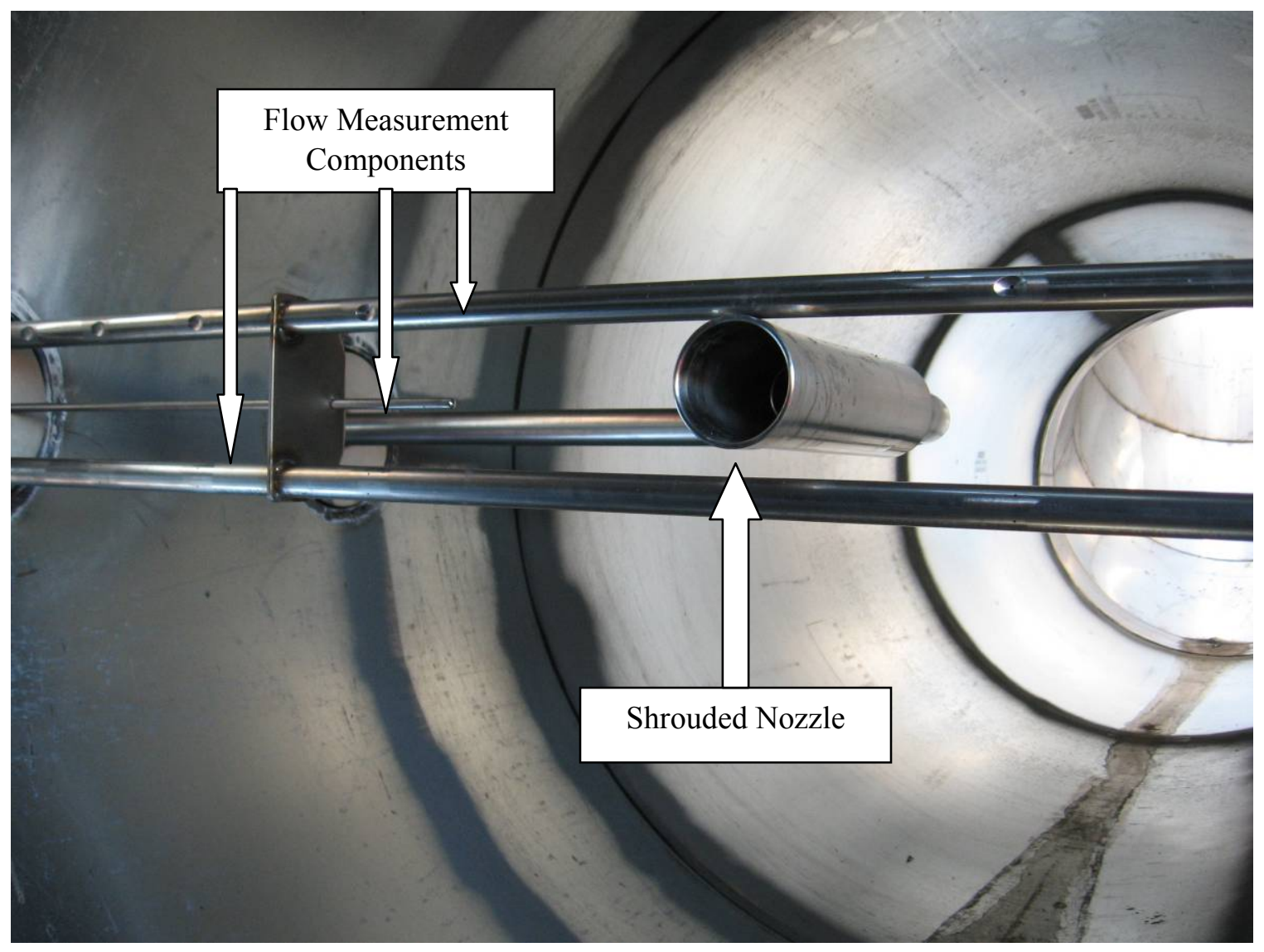

Figure 3.2. Sampling Probe Assembly

\subsection{Flow Angle Test}

The air-velocity vector approaching the sample nozzle should be aligned with the axis of the nozzle, within an acceptable angle, so sample extraction performance is not degraded (see Section 2). The test method is based on 40 CFR 60, Appendix A, Method 1, Section 11.4.

The "flow angle" is the average angle between the air velocity vector and the axis of the sampling nozzle. The flow angle was measured at a grid of points in a cross section of the 3430 Building Filtered Exhaust Stack at the test ports just a few inches upstream of the actual sampling probe. The grid is an array of points in an x-pattern in the cross section of the duct. One line of points is aligned in the same direction as the sampling probe assembly. The other line is perpendicular to the sample probe assembly. The number and distance between measurement points is based on the U.S. Environmental Protection Agency's (EPA's) method in 40 CFR 60, Appendix A, Method 1.

Measurements were made using a S-type Pitot tube (Dwyer Instruments, 160S-72, Michigan City, IN) attached by flexible tubing to a slant tube manometer (Dwyer Instruments, 400-S), and an angleindicating device. PNNL operating procedure EMS-JAG-05, "Test to Determine Flow Angle," was used to determine the mean flow angle. 
Figure 3.3 is a view looking upstream from the test ports toward the exhaust fans. The S-type Pitot tube is installed in the duct attached to an angle-indicating device threaded to the top test port. Figure 3.4 shows the slant-tube manometer.

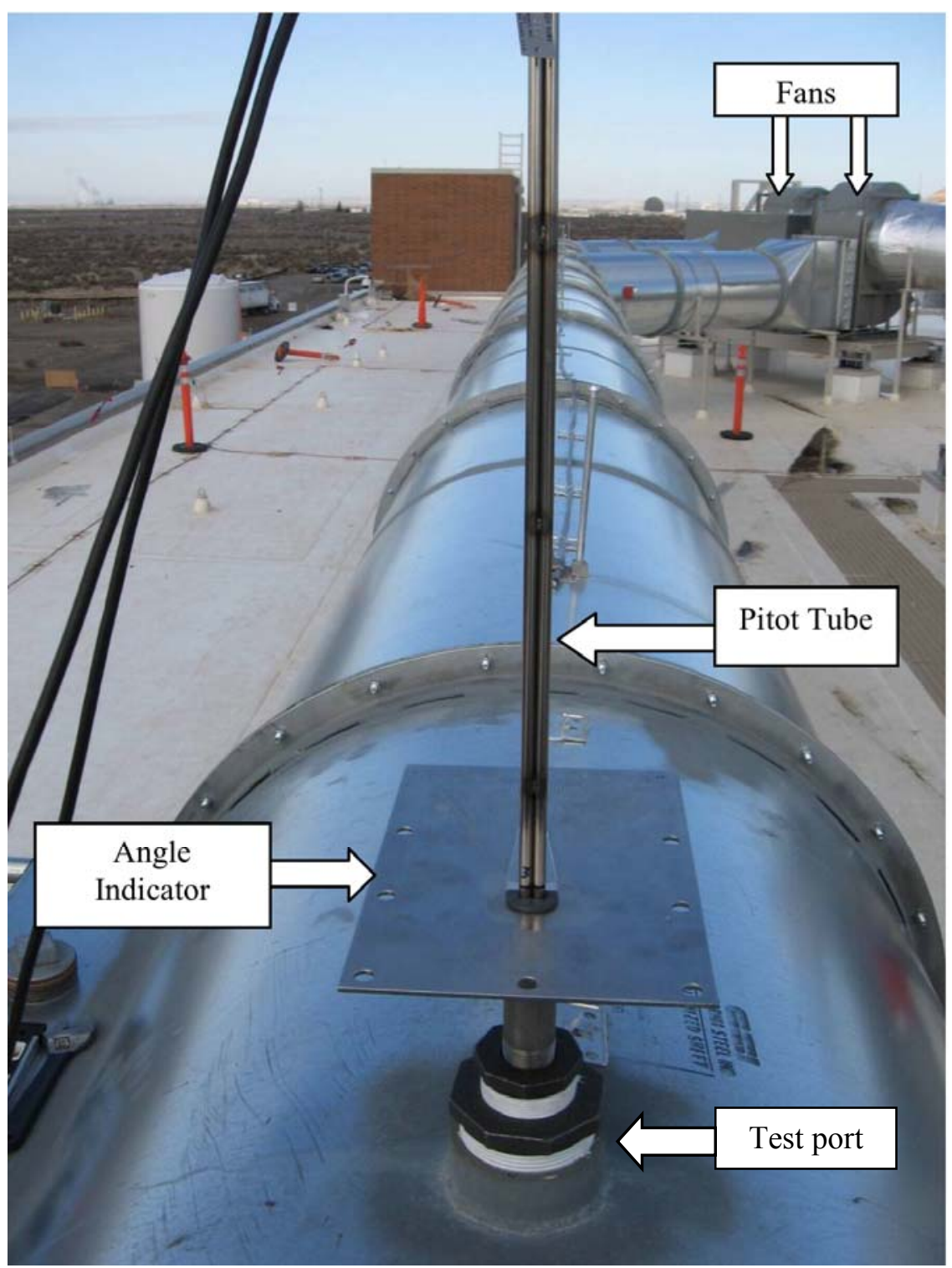

Figure 3.3. Flow Angle Indicator and Pitot Tube Installed 


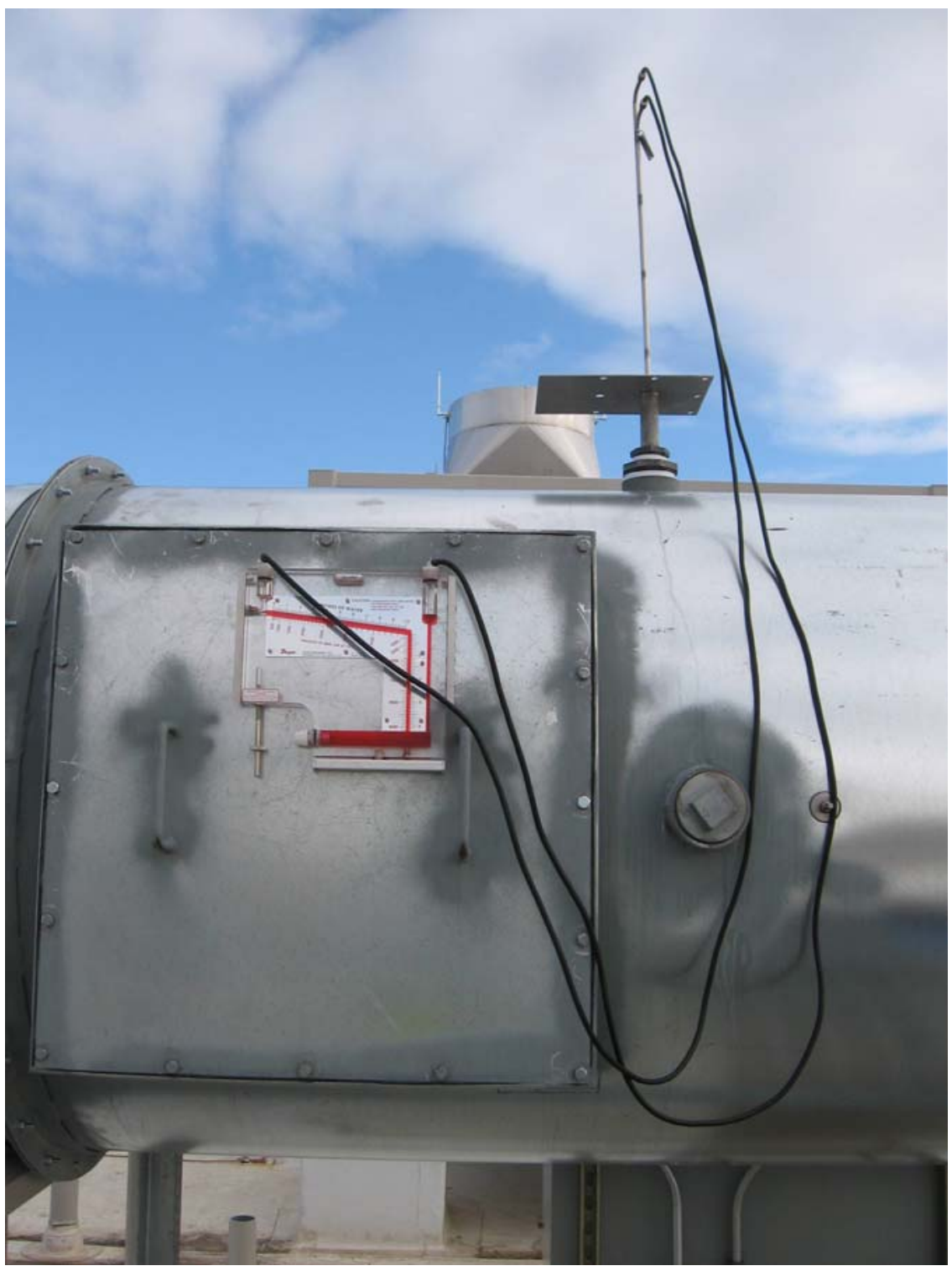

Figure 3.4. Slant Tube Manometer on Inspection Hatch Cover

\subsection{Velocity Uniformity Test}

To determine uniformity, air velocity is measured at the same grid of points used for the flow angle test. The method used is based on 40 CFR 60, Appendix A, Method 1.

The air velocity is measured three times at each grid point, and each measurement is recorded. The measurements at each grid point are averaged to determine the mean velocity at each grid point. The average values for each grid point in the center two thirds of the stack are used to calculate the mean and standard deviation of velocity for the sampling location. The \% COV is calculated as 100 times the standard deviation divided by the mean. This value should be less than or equal to $9.7 \%$ for the scale model tests to apply to the stack. 
The test equipment used included an S-type Pitot tube and a calibrated electronic manometer (GrayWolf, ZephyrII+, Shelton, CT) as shown in Figure 3.5. The Pitot tube is inserted in the duct as shown in Figure 3.4, except an electronic manometer is used in place of the slant-tube manometer. The electronic manometer indicates actual air velocity, assuming a Pitot tube correction factor of 1 . Because the S-type Pitot tube has a correction factor of 0.84 , the recorded values were corrected after the test. PNNL operating procedure EMS-JAG-04 "Test to Determine Uniformity of Air Velocity at a Sampler Probe," was used for this test.

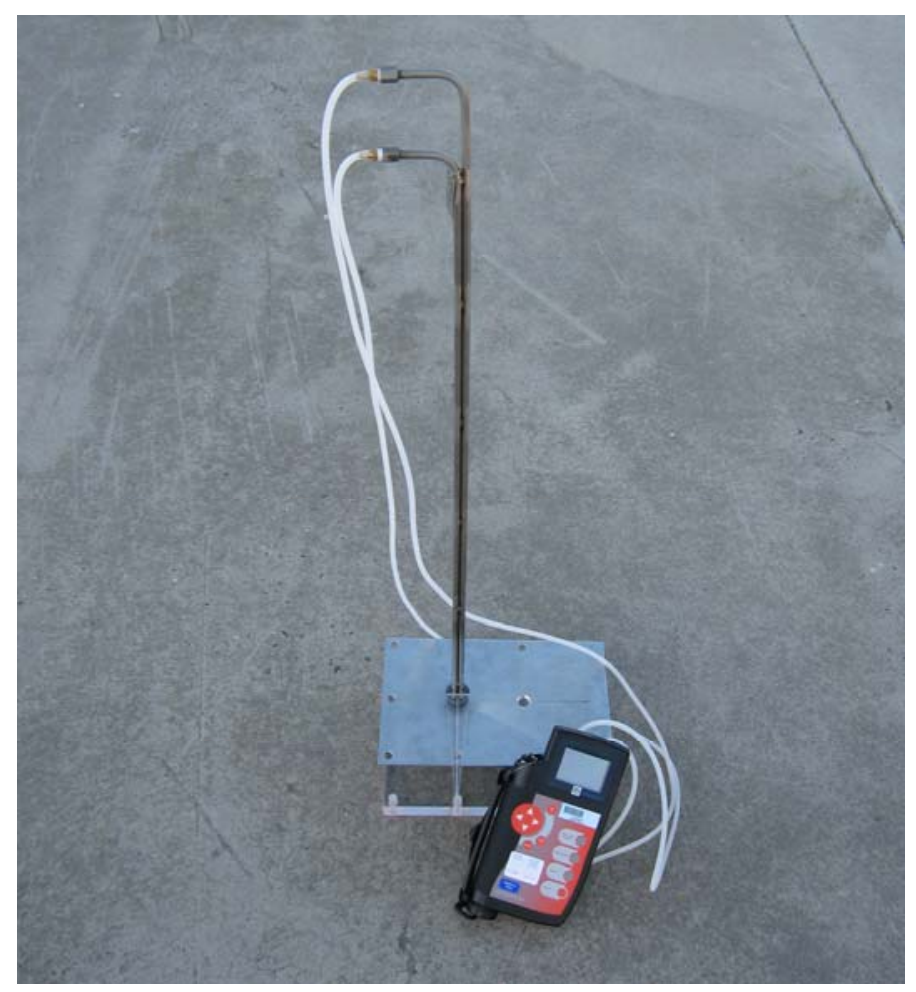

Figure 3.5. Electronic Manometer Connected to Pitot Tube

\subsection{Quality Assurance}

The PNNL Quality Assurance (QA) Program is based upon the requirements as defined in the U.S. Department of Energy (DOE) Order 414.1C, Quality Assurance and 10 CFR 830, Energy/Nuclear Safety Management, Subpart A-Quality Assurance Requirements (a.k.a., the Quality Rule). PNNL has chosen to implement the following consensus standards in a graded approach:

- American Society of Mechanical Engineers (ASME) NQA-1-2000, Quality Assurance Requirements for Nuclear Facility Applications, Part 1, Requirements for Quality Assurance Programs for Nuclear Facilities.

- ASME NQA-1-2000, Part II, Subpart 2.7, Quality Assurance Requirements for Computer Software for Nuclear Facility Applications.

- ASME NQA-1-2000, Part IV, Subpart 4.2, Graded Approach Application of Quality Assurance Requirements for Research and Development. 
The procedures necessary to implement the requirements are documented in PNNL's standards-based management system called "How Do I...?" (HDI). ${ }^{\text {(a) }}$

The Stack Monitoring Project (STMON) implements a National Quality Assurance (NQA)-1-2000 Quality Assurance Program, graded on the approach presented in NQA-1-2000, Part IV, Subpart 4.2. The STMON Quality Assurance Manual (QA-STMON-0002 ${ }^{(\mathrm{b})}$ ) describes the technology life cycle stages under the STMON Quality Assurance Plan (QA-STMON-0001 ${ }^{(\mathrm{c})}$ ). The technology life cycle includes the progression of technology development, commercialization, and retirement in process phases of basic and applied research and development $(\mathrm{R} \& \mathrm{D})$, engineering, and production and operation until process completion. The life cycle is characterized by flexible and informal QA activities in basic research, which becomes more structured and formalized through the applied R\&D stages:

- BASIC RESEARCH - Basic research consists of research tasks that are conducted to acquire and disseminate new scientific knowledge. During basic research, maximum flexibility is desired to allow the researcher the necessary latitude to conduct the research.

- APPLIED RESEARCH - Applied research consists of research tasks that acquire data and documentation necessary to make sure that results can be satisfactorily reproduced. The emphasis during this stage of a research task is on achieving adequate documentation and controls necessary to be able to reproduce results.

- DEVELOPMENTAL WORK - Developmental Work consists of research tasks moving toward technology commercialization. These tasks still require a degree of flexibility, and there is still a degree of uncertainty that exists in many cases. The role of quality on Developmental Work is to make sure that adequate controls to support movement into commercialization exist.

- RESEARCH AND DEVELOPMENT SUPPORT ACTIVITIES - Support activities are those that are conventional and secondary in nature to the advancement of knowledge or development of technology, but allow the primary purpose of the work to be accomplished in a credible manner. An example of a support activity is controlling and maintaining documents and records. The level of quality for these activities is the same as for developmental work.

The work described in this report has been completed under the QA technology level of Development Work. STMON addresses internal verification and validation activities by conducting an independent technical review of the final data report in accordance with STMON's procedure QA-STMON-601, ${ }^{(\mathrm{d})}$ "Document Preparation and Change." This review verifies that the reported results are traceable, that inferences and conclusions are soundly based, and that the reported work satisfies the Test Plan objectives.

The tests were conducted according to an approved test plan and test instructions. Data transcription and calculations were independently reviewed.

(a) A system for managing the delivery of laboratory-level policies, requirements, and procedures.

(b) QA-STMON-0002, Rev. 0. January 2, 2010. "Pacific Northwest National Laboratory Stack Monitoring Project Quality Assurance Manual.” Pacific Northwest National Laboratory, Richland, Washington.

(c) QA-STMON-0001, Rev. 0. January 2, 2010. "Pacific Northwest National Laboratory Stack Monitoring Project Quality Assurance Plan.” Pacific Northwest National Laboratory, Richland, Washington.

(d) QA-STMON-0601, Rev. 0. January 2, 2010. "Document Preparation and Change.” Pacific Northwest National Laboratory, Richland, Washington. 


\subsection{Test Results}

Independent reviews were performed to verify the data transcription and calculations. The final data sheets are attached in Appendix A.

The duct diameters were field measured at the test ports and found to be $43.75 \mathrm{in}$. as listed in Table 4.1. The distance from the test ports to the nearest upstream disturbance (the junction of the ducts from the fans) was $53.5 \mathrm{ft}^{\mathrm{a}}$. Therefore, in terms of duct diameters (DIA = distance divided by the duct diameter), the tests were performed 14.7 DIA downstream of the duct junction. In comparison, the test ports in the model tested by Glissmeyer and Droppo (2007) were 4.45 DIA, 9.47 DIA, and 14.5 DIA for Test Ports 1, 2, and 3, respectively, downstream of the junction.

Table 4.1. Test Port Depth Measurements

\begin{tabular}{ccc}
\hline Side of duct & $\begin{array}{c}\text { Measurement } \\
\text { Port }\end{array}$ & $\begin{array}{c}\text { Measured Duct } \\
\text { Depth, in. }\end{array}$ \\
\hline Top & 1 & 43.75 \\
West Side & 2 & 43.75 \\
\hline
\end{tabular}

\subsection{Velocity Uniformity Results}

The measured air velocity \% COV values are summarized in Table 4.2, which also lists the airflow calculated from the velocity measurements for each velocity uniformity test run (VT). VT-1 through VT3 were conducted during January 2010, while VT-4 through VT-7 were conducted during May 2010. For the January tests, the average result was 3.5\% COV, while the May test average was $3.6 \%$ COV with two fans running. These results are both well within the acceptance criterion derived in Section $2.1(<9.7 \%$ COV) for verifying that the 3430 Building Filtered Exhaust Stack configuration is represented by the model tests of Glissmeyer and Droppo (2007).

\footnotetext{
${ }^{a}$ The data sheets from the January 2010 stack tests incorrectly report the distance to disturbance as $74.5 \mathrm{ft}$. This was the distance from the port to the far end of the duct junction, whereas the near end of the duct junction (the correct distance) was $53.5 \mathrm{ft}$.
} 
Table 4.2. 3430 Building Filtered Exhaust Stack Velocity Uniformity Test Runs

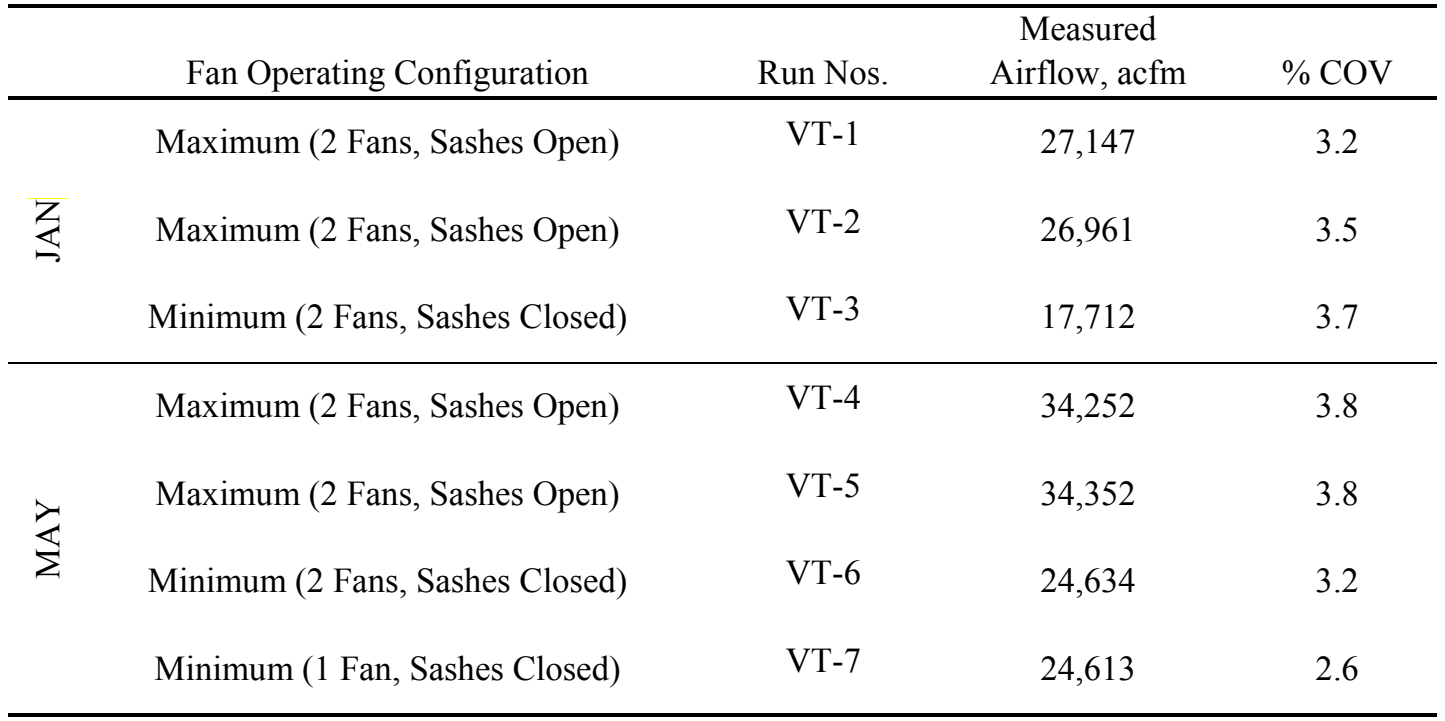

\subsection{Flow Angle Results}

The results for the flow angle test runs (FAs) are listed in Table 4.3. The airflow displayed in the air sampling cabinet, which is listed in units of standard cubic feet per minute (scfm), is included in this table as well. FA-1 through FA-3 were conducted during January 2010, while FA-4 through FA-7 were conducted during May 2010. For both the January and May tests, the average flow angle was $2.6^{\circ}$. This result is acceptable and well within the acceptance criterion of $20^{\circ}$.

Table 4.3. 3430 Building Filtered Exhaust Stack Flow Angle Test Runs

\begin{tabular}{|c|c|c|c|c|}
\hline & Fan Operating Configuration & Run Nos. & $\begin{array}{c}\text { Airflow Displayed in } \\
\text { Sampling Cabinet ,scfm }\end{array}$ & $\begin{array}{l}\text { Mean Absolute } \\
\text { Flow Angle }\end{array}$ \\
\hline \multirow{3}{*}{ 芯 } & Maximum (2 Fans, Sashes Open) & FA-1 & 27,400 & 2.8 \\
\hline & Maximum (2 Fans, Sashes Open) & FA-2 & 27,300 & 2.2 \\
\hline & Minimum (2 Fans, Sashes Closed) & FA-3 & 17,000 & 2.9 \\
\hline \multirow{4}{*}{ 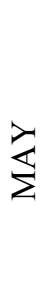 } & Maximum (2 Fans, Sashes Open) & FA-4 & 31,650 & 1.8 \\
\hline & Maximum (2 Fans, Sashes Open) & FA-5 & 31,250 & 2.6 \\
\hline & Minimum (2 Fans, Sashes Closed) & FA-6 & 23,150 & 2.9 \\
\hline & Minimum (1 Fan, Sashes Closed) & FA-7 & 23,300 & 3.0 \\
\hline
\end{tabular}




\subsection{Conclusions}

Velocity uniformity tests were performed on the 3430 Building Filtered Exhaust Stack during both January and May 2010. Tests were conducted in May to ensure that modifications made to the exhaust system after the January testing did not negatively affect the validity of adopting the results of the previously conducted scale testing. Both tests showed acceptable agreement with the scale model tests performed previously (Glissmeyer and Droppo 2007), and the current location for the air sampling probe meets the qualification criteria given in ANSI/HPS-1999. The gas and particle tracer qualification results of the scale model apply equally to the full-sized stack. The results from Glissmeyer and Droppo (2007) are included in Appendix B of this report. The results for the flow angle test on the 3430 Building Filtered Exhaust Stack also show compliance with the flow-angle criterion. 


\subsection{References}

10 CFR 830, Subpart A. 2008. "Quality Assurance Requirements.” Code of Federal Regulations, U.S. Department of Energy.

40 CFR 60, Appendix A, Method 1. 2008. "Sample and Velocity Traverses for Stationary Sources." Code of Federal Regulations, U.S. Environmental Protection Agency.

40 CFR 61, Subpart H. 2002. "National Emission Standard For Emissions of Radionuclides Other Than Radon from Department of Energy Facilities.” Code of Federal Regulations, U.S. Environmental Protection Agency.

American Society of Mechanical Engineers (ASME). 2000a NQA-1-2000, "Quality Assurance Requirements for Nuclear Facility Applications, Part 1, Requirements for Quality Assurance Programs for Nuclear Facilities." New York, New York.

American Society of Mechanical Engineers (ASME). 200b. NQA-1-2000, Part II, Subpart 2.7, "Quality Assurance Requirements for Computer Software for Nuclear Facility Applications.” New York, New York.

American Society of Mechanical Engineers (ASME). 2000c. NQA-1-2000, Part IV, Subpart 4.2, "Graded Approach Application of Quality Assurance Requirements for Research and Development." New York, New York.

American National Standards Institute/Health Physical Society (ANSI/HPS). 1999. Sampling and Monitoring Releases of Airborne Radioactive Substances from the Stack and Ducts of Nuclear Facilities. N13.1-1999. Health Physics Society, McLean, Virginia.

DOE Order 414.1C. Quality Assurance. U.S. Department of Energy, Washington, D.C.

Glissmeyer JA and JG Droppo. 2007. Assessment of the HV-C2 Stack Sampling Probe Location. PNNL-16611, Pacific Northwest National Laboratory, Richland, Washington.

EMS-JAG-04, Rev. 2. Test to Determine Uniformity of Air Velocity at a Sampler Probe. Pacific Northwest National Laboratory, Richland, Washington.

EMS-JAG-05, Rev. 2. Test to Determine Flow Angle. Pacific Northwest National Laboratory, Richland, Washington. 

Appendix A

Data Sheets 


\section{Appendix A: Data Sheets}

FLOW ANGLE DATA FORM

\begin{tabular}{|c|c|c|c|}
\hline FLOW ANGLE DA & TA FORM & & FlowAngleRev0.xls \\
\hline Site & 3430 Stack & & \\
\hline Date & $1 / 6 / 2010$ & & \\
\hline Tester & JAG/JEF & & \\
\hline Stack Dia. & 43.75 & in & \\
\hline Stack X-Area & 1503.3 & in2 & \\
\hline Elevation & N.A. & $\mathrm{ft}$ & \\
\hline Distance to disturbance & 74.5 & $\mathrm{ft}$ & \\
\hline Start/End Time & $1055 / 1140$ & & \\
\hline
\end{tabular}

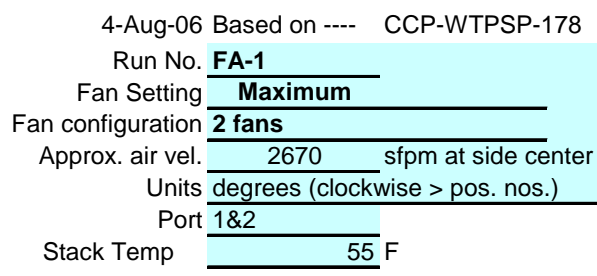

4-Aug-06 Based on ---- CCP-WTPSP-178 Run No. FA-1

Fan Setting Maximum

Fan configuration 2 fans

Approx. air vel. 2670 sfpm at side center Units degrees (clockwise $>$ pos. nos.) Port $1 \& 2$

Stack Temp $55 \mathrm{~F}$

Order -->

Traverse-->

Trial ---->

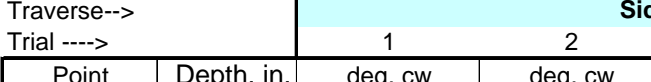

\begin{tabular}{|c|r|c|c|c|c|}
\hline Point & Depth, in. & deg. cw & deg. Cw & deg. cw & A \\
\hline 1 & 1.40 & 8 & 8 & 8 & 8.0 \\
\hline 2 & 4.58 & 0 & 0 & 5 & 1.7 \\
\hline 3 & 8.46 & -2 & 0 & 0 & -0.7 \\
\hline 4 & 14.09 & -5 & -4 & 0 & -3.0 \\
\hline Center & 21.81 & -4 & 0 & 0 & -1.3 \\
\hline 5 & 29.53 & -4 & -1 & -5 & -3.3 \\
\hline 6 & 35.16 & -5 & -3 & -4 & -4.0 \\
\hline 7 & 39.04 & -4 & -3 & -3 & -3.3 \\
\hline 8 & 42.23 & -3 & -4 & -2 & -3.0 \\
\hline
\end{tabular}

Mean of absolute values of all data: w/o points by wall:

3.1

Instuments Used: S-type pitot Velocity sensor Angle indicator Manometer

\begin{tabular}{ll} 
Cal. Due & \\
\cline { 2 - 2 } Dwyer 72-inch S-type Pitot\#11 160S-72-A30U & Cert. of conformance \\
\hline TSI VELOCICALC 209060 & $7 / 14 / 2010$ \\
\hline Shop built
\end{tabular}

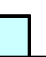
Top

\begin{tabular}{|c|c|c|c|}
\hline \multicolumn{4}{|c|}{ Top } \\
\hline 1 & 2 & 3 & \\
\hline deg. cw & deg. cw & deg. cw & Avg. \\
\hline 2 & 3 & 2 & 2.3 \\
\hline-5 & -2 & -1 & -2.7 \\
\hline 1 & 1 & 1 & 1.0 \\
\hline 0 & 0 & -1 & -0.3 \\
\hline-1 & -1 & -1 & -1.0 \\
\hline-2 & -1 & -2 & -1.7 \\
\hline-3 & -3 & -3 & -3.0 \\
\hline-4 & -4 & -4 & -4.0 \\
\hline-6 & -5 & -5 & -5.3 \\
\hline & & & 2.4 \\
\hline & & & 2.0 \\
\hline & & al & 2.8 \\
\hline & & w/o wall pts & 2.2 \\
\hline
\end{tabular}

Note:

To assure similar hose connections between the manometer and pitot tube, rotating the pitot tube assembly clockwise drives the meniscus to the right (to higher pos. numbers).
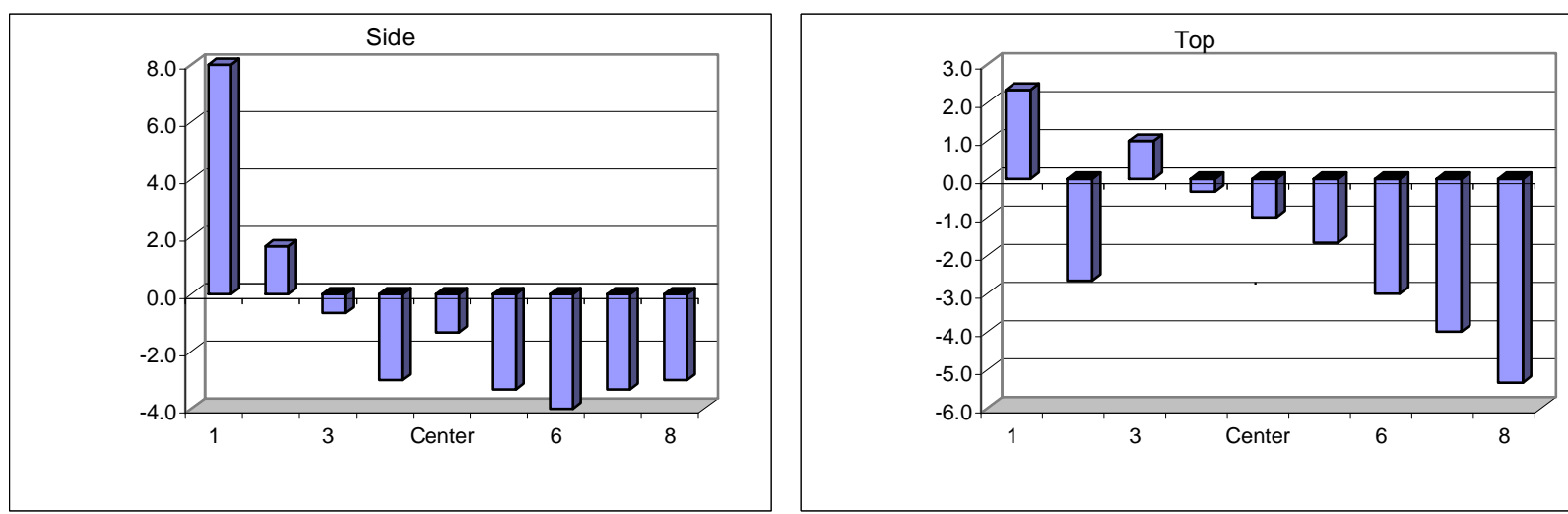

Air sampler Masstron shows 27,400 scfm stack flow. All hood sashes open

Notes: 


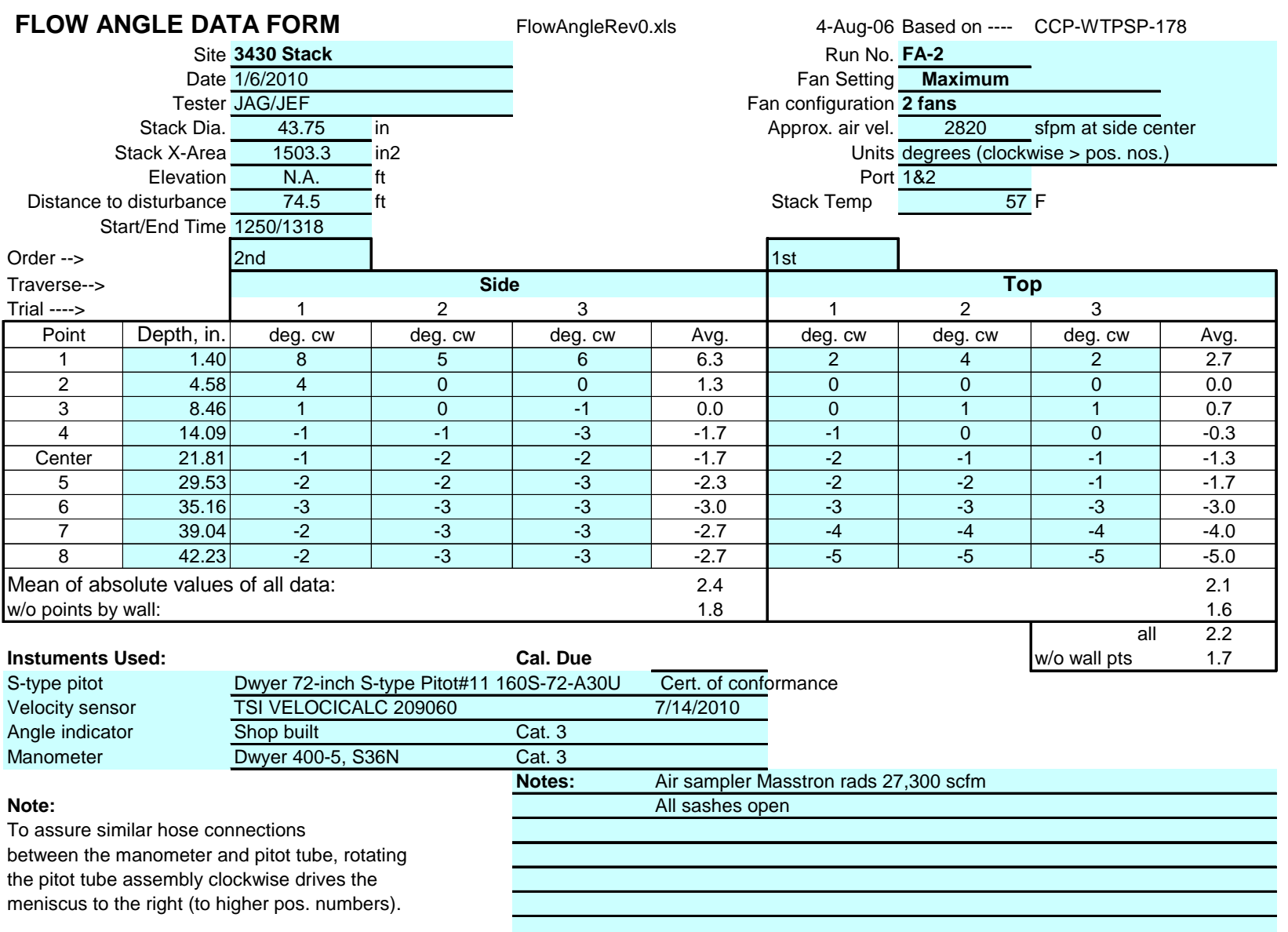

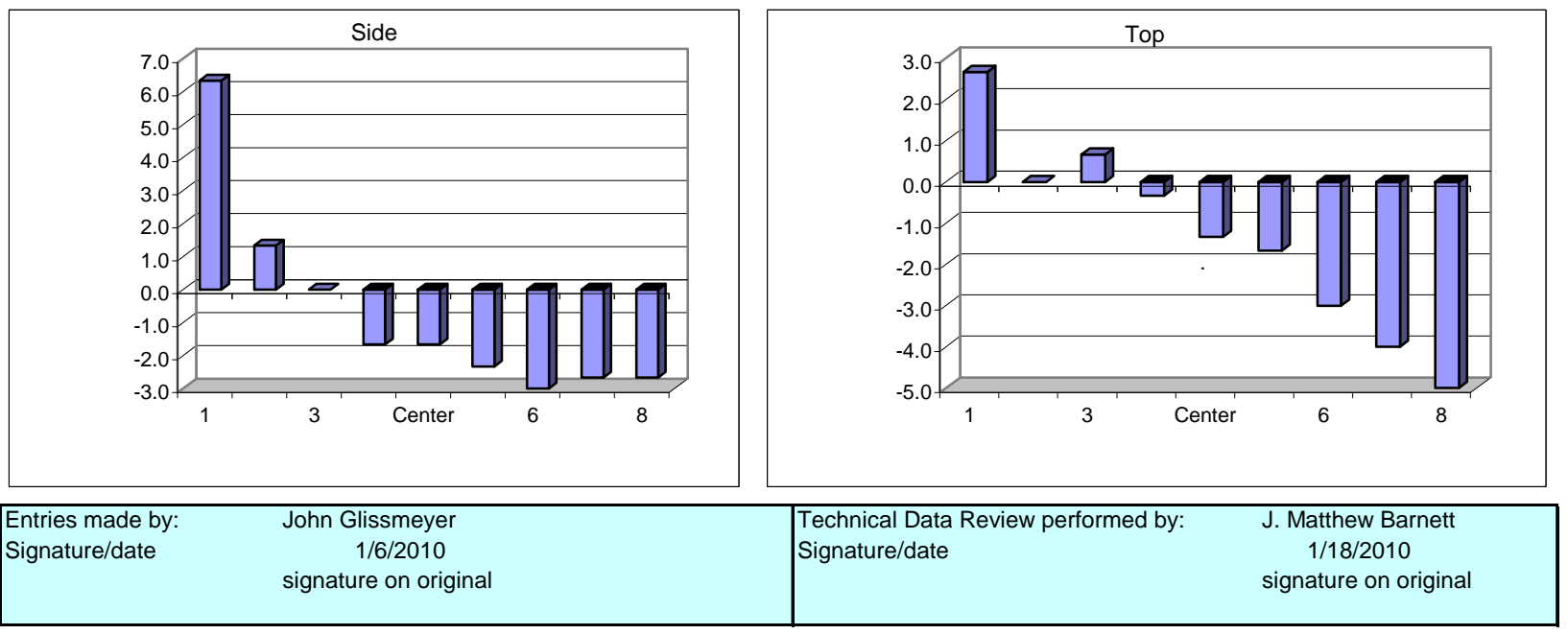


FLOW ANGLE DATA FORM

Site 3430 Stack

Date $1 / 7 / 2010$

Tester JAG/DMT

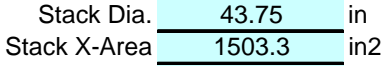

Elevation $\mathrm{N}$.A. $\mathrm{ft}$

Distance to disturbance $\frac{74.5}{\mathrm{ft}}$

Start/End Time 1230/1325
FlowAngleRev0.xls

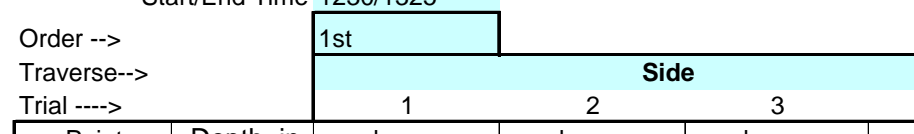

4-Aug-06 Based on ---

CCP-WTPSP-178

Run No. FA-3

Fan Setting Minimum, night setback Fan configuration $\mathbf{1 \text { \& } \mathbf { 2 }}$

Approx. air vel. 1740 sfpm at side center Units degrees (clockwise $>$ pos. nos.)

Port $1 \& 2$

Stack Temp $58 \mathrm{~F}$

Trial ---->

\begin{tabular}{|c|r|c|r|}
\hline Point & Depth, in. & deg. cw & deg \\
\hline 1 & 1.40 & 8 & 7 \\
\hline 2 & 4.58 & 4 & 5 \\
\hline 3 & 8.46 & -1 & 2 \\
\hline 4 & 14.09 & -2 & -2 \\
\hline Center & 21.81 & -4 & -3 \\
\hline 5 & 29.53 & -3 & -3 \\
\hline 6 & 35.16 & -2 & -3 \\
\hline 7 & 39.04 & -3 & -4 \\
\hline 8 & 42.23 & -4 & -5 \\
\hline
\end{tabular}

Mean of absolute values of all data: w/o points by wall:

\begin{tabular}{c|c}
\hline eg. cw & deg \\
\hline 7 & \\
\hline 5 & -1 \\
\hline 2 & -3 \\
\hline-2 & -3 \\
\hline-3 & -4 \\
\hline-3 & -3 \\
\hline-3 & -3 \\
\hline-4 & -4 \\
\hline
\end{tabular}

Who poins by wal:

Instuments Used:

S-type pitot

Velocity sensor

Angle indicator

Manometer

\begin{tabular}{l} 
Dwyer 72-inch S-type \\
\hline TSI VELOCICALC 209 \\
\hline Shop built \\
\hline Dwyer 400-5, S36N \\
\\
and pitot tube, rotating \\
lockwise drives the
\end{tabular}

Cal. Due

\begin{tabular}{l|r}
\hline 6 & 7.0 \\
\hline 6 & 5.0
\end{tabular}

2

2nd

\begin{tabular}{|c|}
\hline \\
\hline Avg. \\
\hline 7.0 \\
\hline 5.0 \\
\hline 0.0 \\
\hline-2.3 \\
\hline-3.3 \\
\hline-3.3 \\
\hline-2.7 \\
\hline-3.3 \\
\hline-4.3 \\
\hline 3.5 \\
\hline
\end{tabular}

2.9

\begin{tabular}{c|c|c|c|}
\hline \multicolumn{4}{c}{ Top } \\
\hline deg. $\mathrm{cw}$ & 2 & 3 \\
\hline 2 & deg. cw & deg. cw & Avg.
\end{tabular}

\begin{tabular}{|c|c|c|c|}
\hline deg. cw & deg. cw & deg. cw & Avg. \\
\hline 2 & 0 & -6 & -1.3 \\
\hline-4 & -4 & -3 & -3.7 \\
\hline-2 & -3 & 1 & -1.3 \\
\hline-3 & -1 & -1 & -1.7 \\
\hline-2 & -2 & -2 & -2.0 \\
\hline 0 & -2 & -2 & -1.3 \\
\hline-3 & -3 & -3 & -3.0 \\
\hline-2 & -3 & -3 & -2.7 \\
\hline-5 & -5 & -3 & -4.3 \\
\hline & & & 2.4 \\
\hline & & & 2.2 \\
\hline & & w/o wall pts & $\begin{array}{l}2.9 \\
2.5\end{array}$ \\
\hline
\end{tabular}

Note:

To assure similar hose connections

between the manometer and pitot tube, rotating

the pitot tube assembly clockwise drives the

meniscus to the right (to higher pos. numbers).

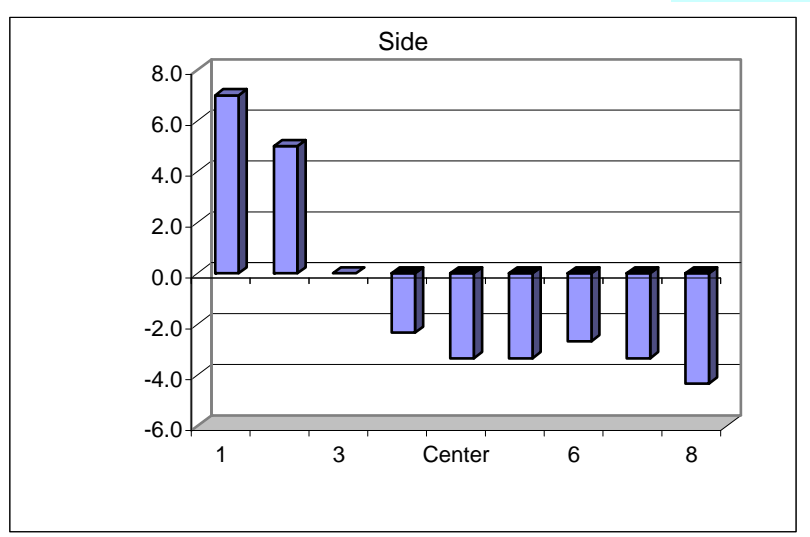

Entries made by: Signature/date

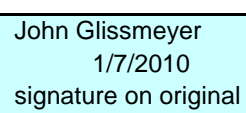

signature on origina

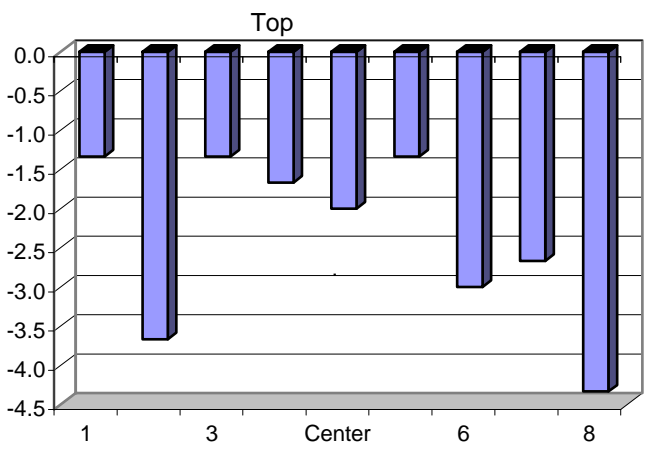

Technical Data Review performed by: Signature/date

Matthew Barnett

$1 / 18 / 2010$

signature on original 


\section{VELOCITY TRAVERSE DATA FORM}

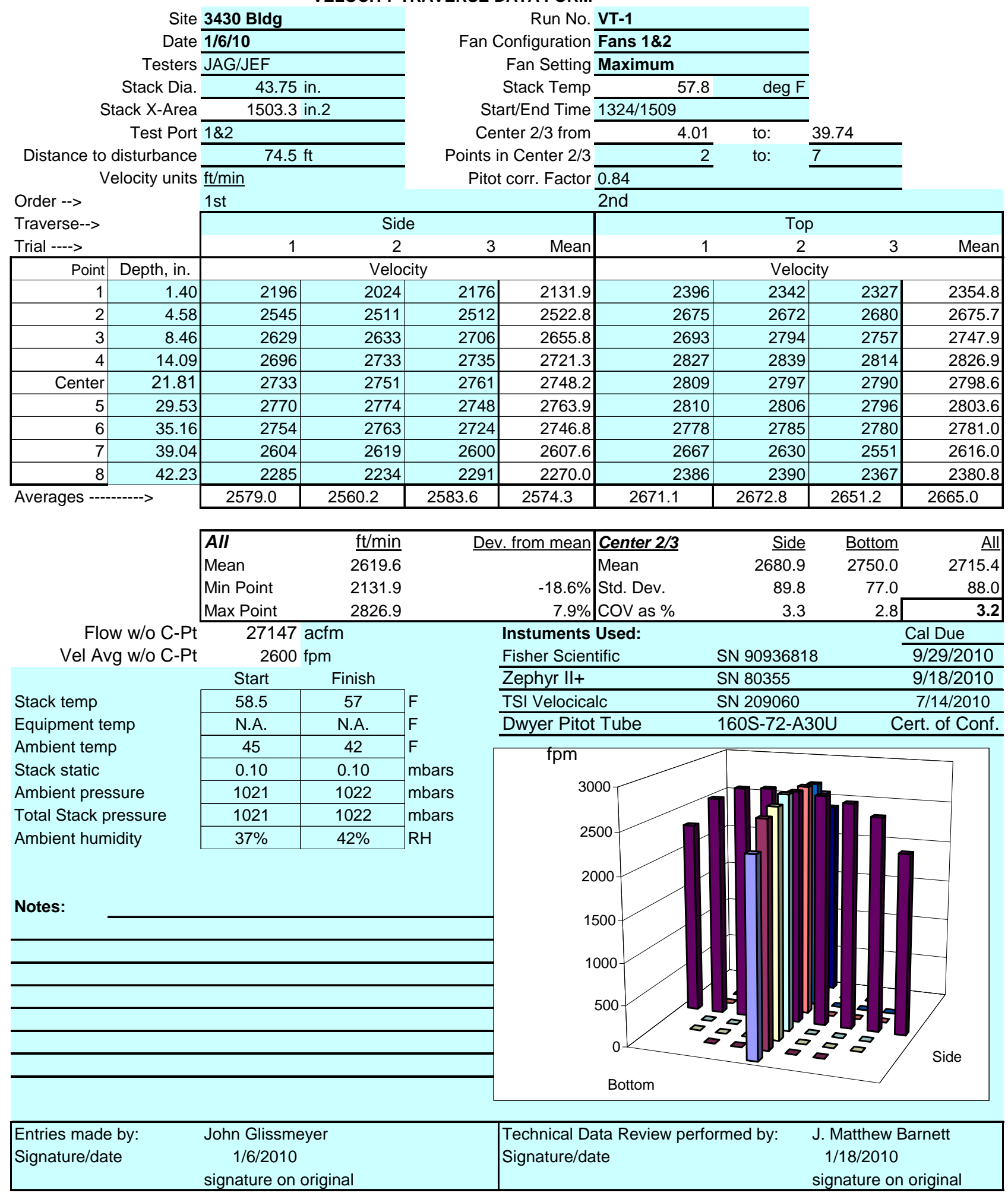




\section{VELOCITY TRAVERSE DATA FORM}

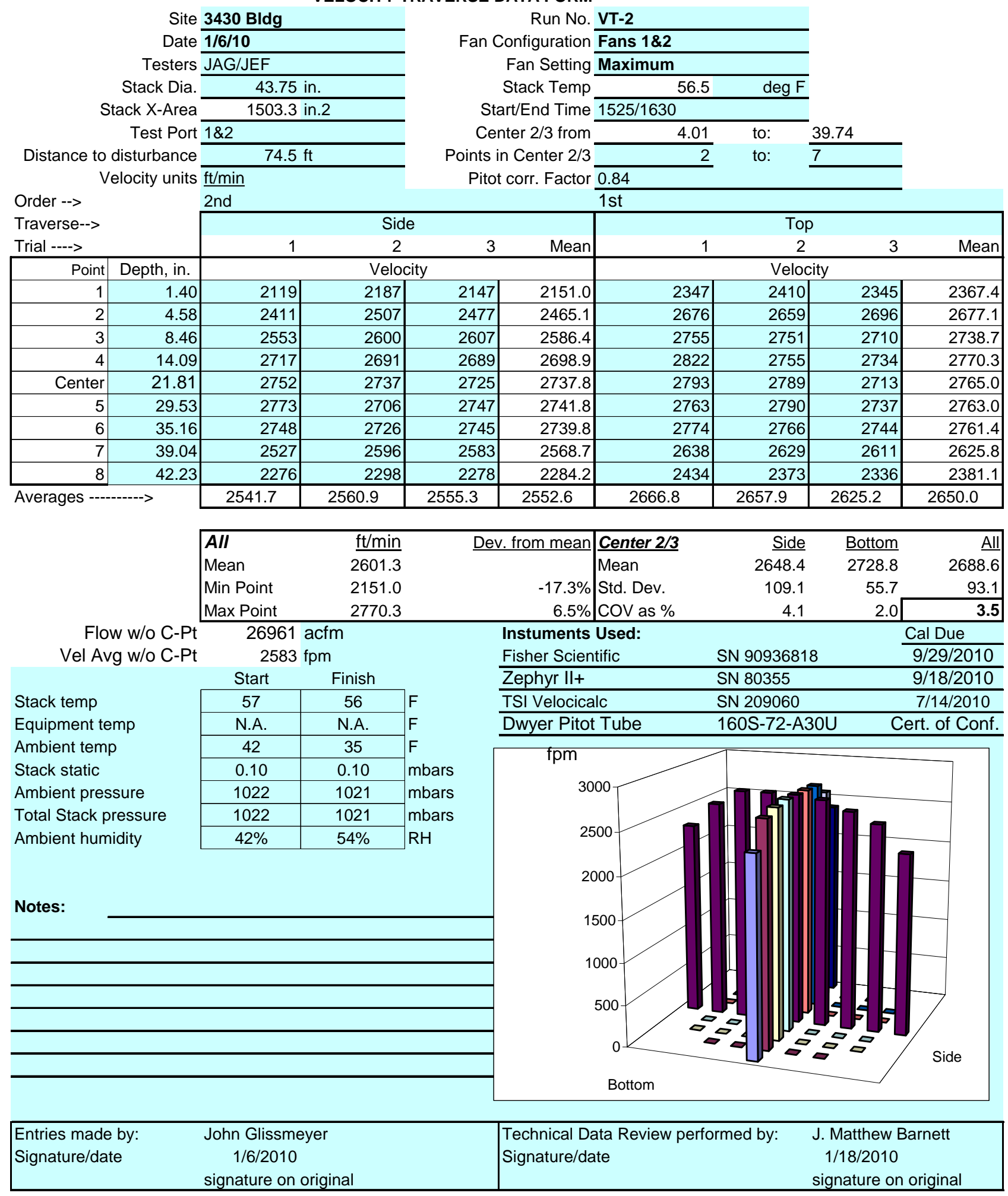




\section{VELOCITY TRAVERSE DATA FORM}

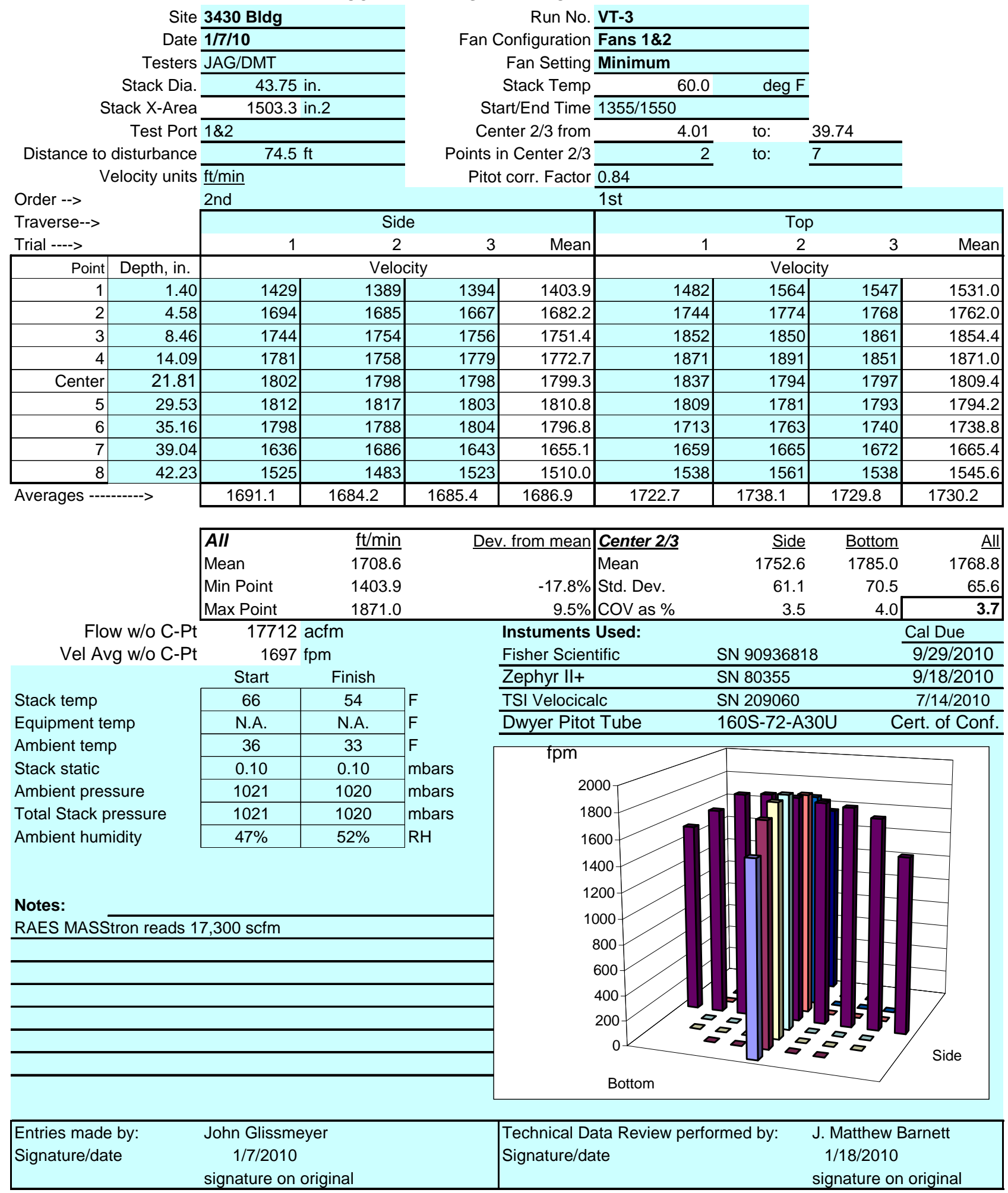


FLOW ANGLE DATA FORM

Site EP-3430-01-S

Date $\overline{5 / 20 / 2010}$

Tester JAG, JEF

\begin{tabular}{rcr} 
Stack Dia. & 43.75 & in \\
Stack X-Area & 1503.3 & in2 \\
\cline { 2 - 2 } Elevation & N.A. & $\mathrm{ft}$ \\
Distance to disturbance & 53.5 & $\mathrm{ft}$ \\
Start/End Time & $1350 / 1435$
\end{tabular}

FlowAngleRevo.xls -

Order -->

Traverse-->

Trial ---->

Trial --->
\begin{tabular}{|c|r|c|c|c|}
\hline Point & Depth, in. & deg. cw & deg. cw & deg. cw \\
\hline 1 & 1.40 & -3 & -7 & -7 \\
\hline 2 & 4.59 & -1 & 0 & -2 \\
\hline 3 & 8.49 & 1 & 1 & 0 \\
\hline 4 & 14.13 & -1 & -1 & -2 \\
\hline Center & 21.88 & 0 & 0 & 0 \\
\hline 5 & 29.62 & -2 & -2 & 0 \\
\hline 6 & 35.26 & -3 & -3 & -2 \\
\hline 7 & 39.16 & -8 & -3 & -3 \\
\hline 8 & 42.35 & -7 & -4 & -4 \\
\hline
\end{tabular}

Mean of absolute values of all data: w/o points by wall:

Instuments Used:

S-type pitot

Velocity sensor

Angle indicator

Manometer

Note:

To assure similar hose connections between the manometer and pitot tube, rotating the pitot tube assembly clockwise drives the meniscus to the right (to higher pos. numbers).

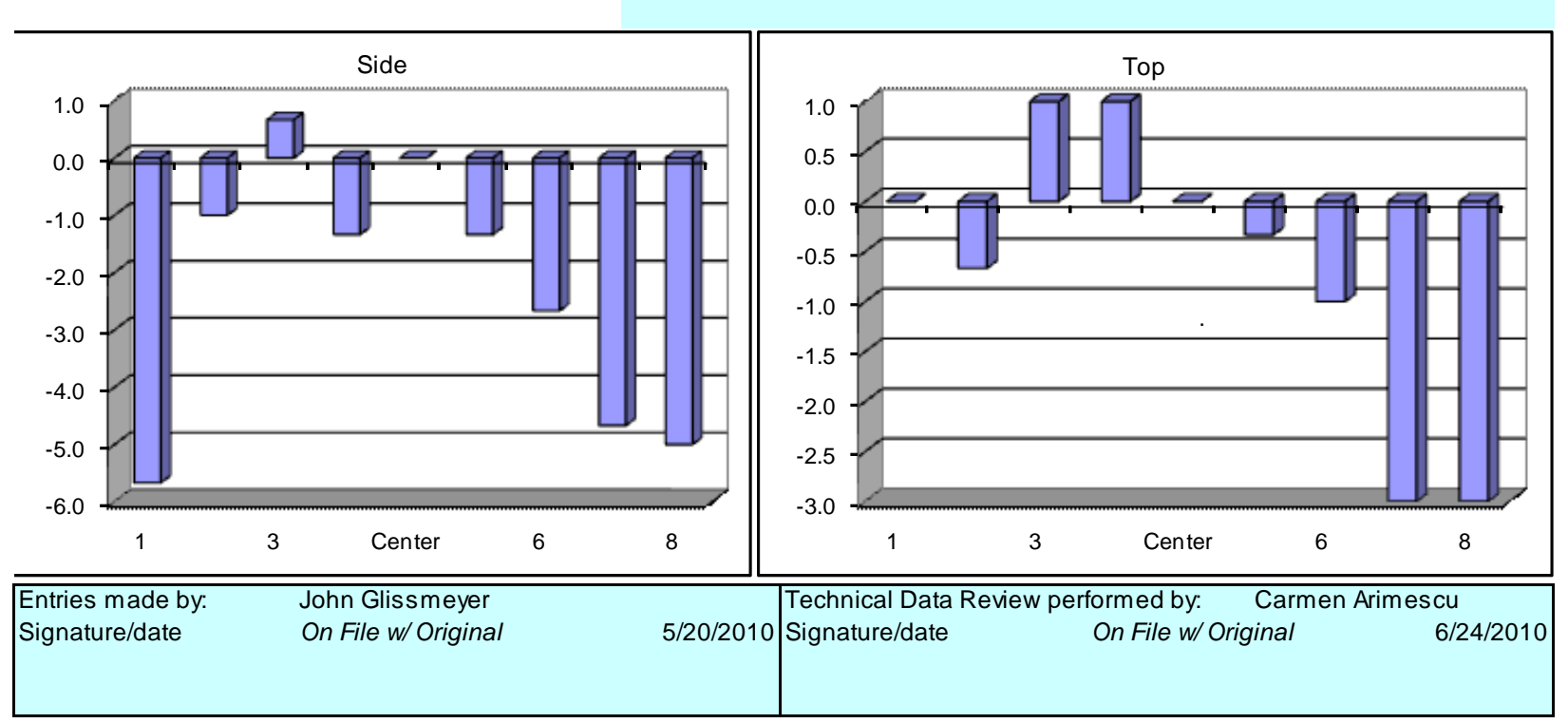

4-Aug-06 Based on ---- CCP-WTPSP-178

Run No. FA-4

Fan Setting Sashes Open

Fan configuration 2 Fans

Approx. air vel. 3460 sfpm at point : side center Units degrees (clockwise $>$ pos. nos.)

Port nearest to probe

Stack Temp 74 deg F 
FLOW ANGLE DATA FORM

Site EP-3430-01-S

Date $5 / 20 / 2010$

Tester JAG, JEF

Stack Dia. 43.75

Stack X-Area 1503.3 in2

Elevation N.A. $\mathrm{ft}$

Distance to disturbance $\overline{53.5} \mathrm{ft}$

Start/End Time $1435 / 1530$
FlowAngleRevo.xls

2 nd

Order -->
Traverse-->

Trial ---->

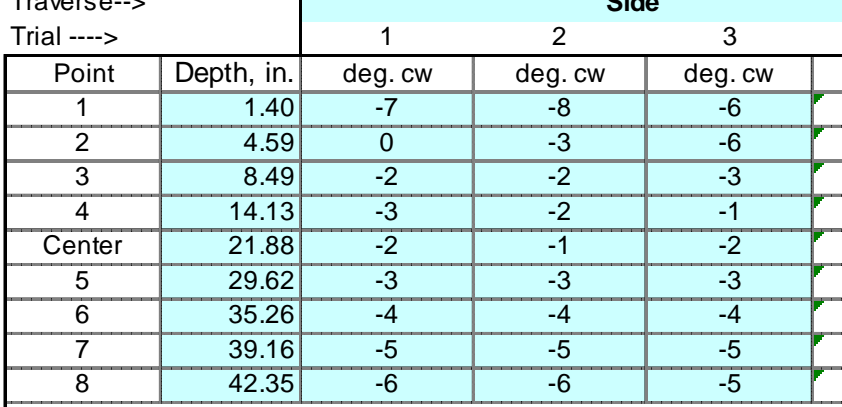

Mean of absolute values of all data:

w/o points by wall:

Instuments Used:

S-type pitot

Velocity sensor

Angle indicator

Manometer

Note:

To assure similar hose connections

between the manometer and pitot tube, rotating

the pitot tube assembly clockwise drives the

meniscus to the right (to higher pos. numbers).

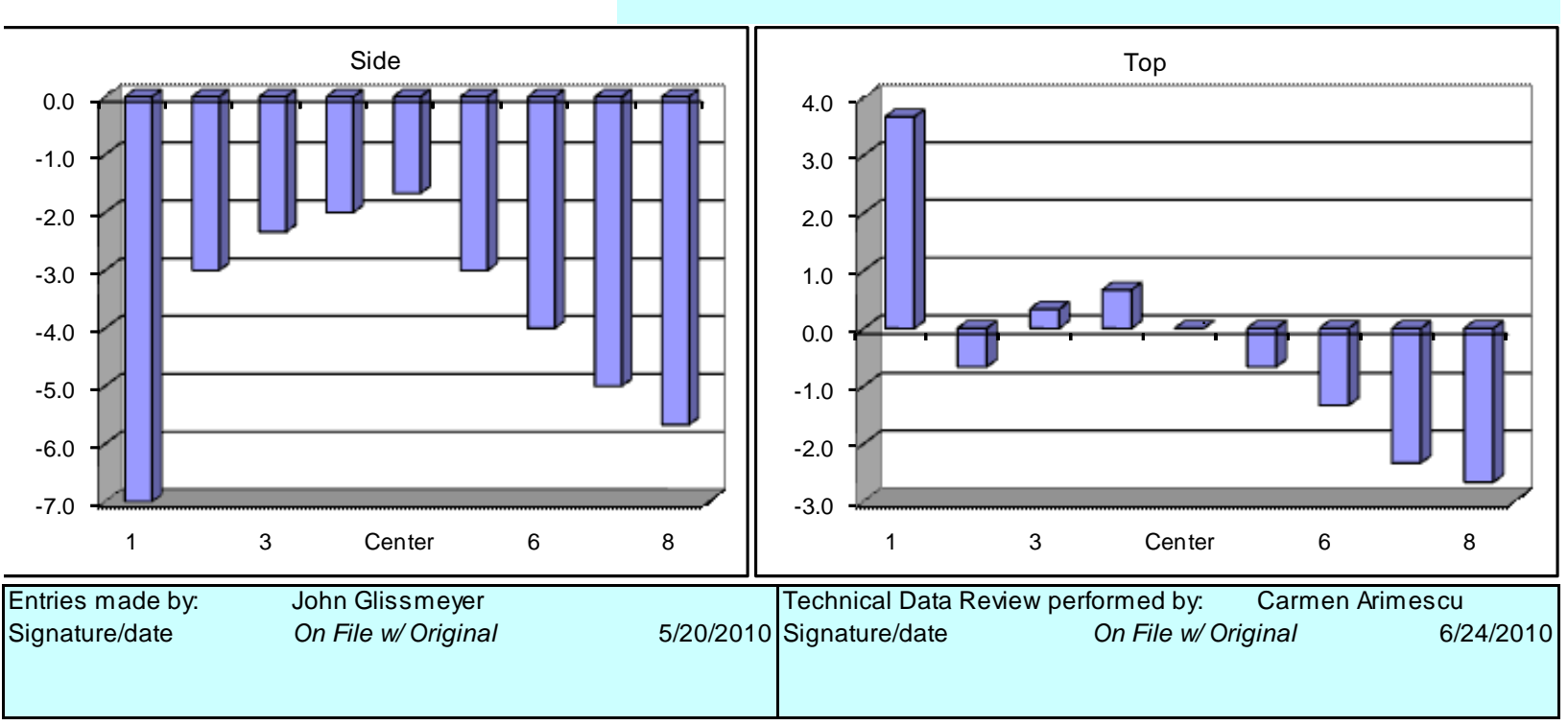




\section{FLOW ANGLE DATA FORM}

Site EP-3430-01-S

Date 5/20/2010

Tester JAG, JEF

Stack Dia. 43.75

Stack X-Area 1503.3 in2

Elevation N.A. $\mathrm{ft}$

Distance to disturbance $\frac{53.5}{\mathrm{ft}}$

Start/End Time $1555 / 1625$
FlowAngleRev0.xls

1 st

1

Order -->

Traverse-->

Trial ---->

\begin{tabular}{|c|c|}
\hline Point & Depth, in. \\
\hline
\end{tabular}

1

\begin{tabular}{l|ll}
1 & 2 & 3
\end{tabular}

\begin{tabular}{|c|r|c|c|c|}
\hline Point & Depth, in. & deg. cw & deg. cw & deg. cw \\
\hline 1 & 1.40 & -7 & -5 & -6 \\
\hline 2 & 4.59 & -5 & -4 & -4 \\
\hline 3 & 8.49 & -1 & -1 & -1 \\
\hline 4 & 14.13 & -4 & -2 & -2 \\
\hline Center & 21.88 & -3 & -2 & -1 \\
\hline 5 & 29.62 & -3 & -3 & -3 \\
\hline 6 & 35.26 & -2 & -3 & -3 \\
\hline 7 & 39.16 & -4 & -4 & -3 \\
\hline 8 & 42.35 & -3 & -6 & -3 \\
\hline
\end{tabular}

Mean of absolute values of all data:

w/o points by wall:

Instuments Used:

S-type pitot

Velocity sensor

Angle indicator

Manometer

Note:

To assure similar hose connections

between the manometer and pitot tube, rotating

the pitot tube assembly clockwise drives the

meniscus to the right (to higher pos. numbers).

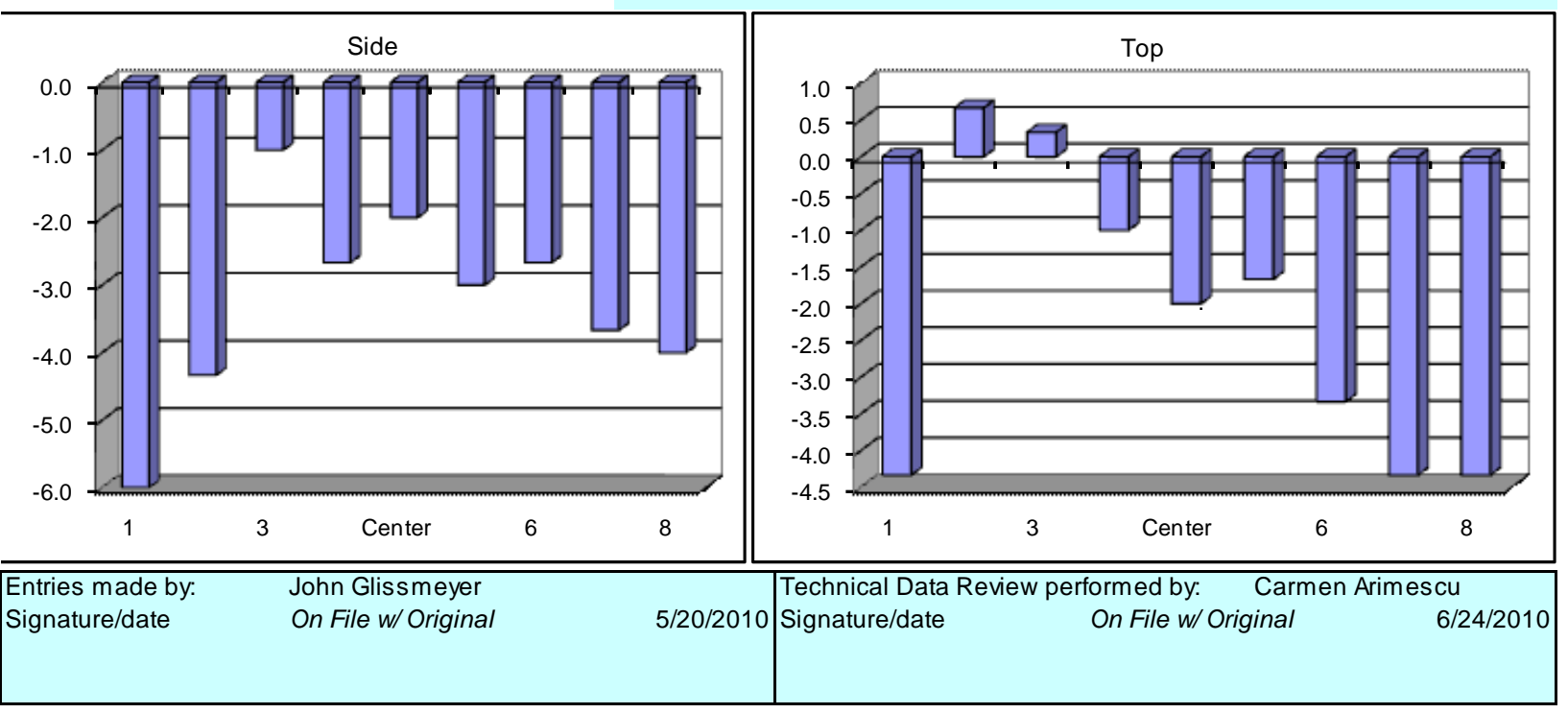


FLOW ANGLE DATA FORM

Site EP-3430-01-S

Date $5 / 21 / 2010$

Tester JAG, JEF

\begin{tabular}{rcr} 
Stack Dia. & 43.75 & in \\
Stack X-Area & 1503.3 & in2 \\
\cline { 2 - 2 } Elevation & N.A. & $\mathrm{ft}$ \\
Distance to disturbance & 53.5 & $\mathrm{ft}$ \\
Start/End Time & $1148 / 1250$
\end{tabular}

FlowAngleRevo.xls

2nd in

(st

Order -->

Trial ---->

\begin{tabular}{|r|r|}
\hline Point & Depth, in. \\
\hline
\end{tabular} Side

\begin{tabular}{|c|r|c|c|c|}
\hline Point & Depth, in. & deg. cw & deg. cw & deg. cw \\
\hline 1 & 1.40 & 12 & 7 & 9 \\
\hline 2 & 4.59 & 6 & 6 & 7 \\
\hline 3 & 8.49 & 1 & 0 & 1 \\
\hline 4 & 14.13 & -1 & -2 & -1 \\
\hline Center & 21.88 & -3 & -2 & -2 \\
\hline 5 & 29.62 & -2 & -2 & -2 \\
\hline 6 & 35.26 & -2 & -2 & -2 \\
\hline 7 & 39.16 & -1 & -1 & -1 \\
\hline 8 & 42.35 & -2 & -2 & -2 \\
\hline
\end{tabular}

Mean of absolute values of all data:

w/o points by wall:

Approx. air vel. 2390 sfpm at point : side center Units degrees (clockwise > pos. nos.)

Port nearest to probe

Stack Temp 71.5 deg F

$1 \mathrm{st}$ 1st

\begin{tabular}{|c|c|c|c|c|}
\hline & \multicolumn{4}{|c|}{ Top } \\
\hline & 1 & 2 & 3 & \\
\hline Avg. & deg. cw & deg. cw & deg. cw & Avg. \\
\hline 9.3 & -3 & 11 & 10 & 6.0 \\
\hline 6.3 & 11 & 5 & 10 & 8.7 \\
\hline 0.7 & 4 & 0 & 2 & 2.0 \\
\hline-1.3 & 0 & -3 & 1 & -0.7 \\
\hline-2.3 & 0 & -3 & 0 & -1.0 \\
\hline-2.0 & -4 & -2 & 0 & -2.0 \\
\hline-2.0 & -4 & -3 & 0 & -2.3 \\
\hline-1.0 & -4 & -4 & 0 & -2.7 \\
\hline-2.0 & -3 & -2 & 0 & -1.7 \\
\hline 3.0 & & & & 3.0 \\
\hline 2.2 & & & & 2.8 \\
\hline & & & $\bar{a}$ & 3.0 \\
\hline Due & & & w/o wall pts & 2.5 \\
\hline
\end{tabular}

Instuments Used:

S-type pitot

Velocity sensor

Angle indicator

Manometer

Dwyer 72-inch S-type Pitot\#11

Cert. of conformance

4-Aug-06 Based on ---- CCP-WTPSP-178

Run No. FA-7

Fan Setting Sashes Down

configuration Near Fan (\#2)

\section{F}




\section{VELOCITY TRAVERSE DATA FORM}

Site EP-3430-01-S

Date $\mathbf{5 / 2 0 / 1 0}$

Testers JAG, JEF

Stack Dia.

Stack X-Area 1503.3

Test Port nearest probe

Distance to disturbance $53.5 \mathrm{ft}$

Velocity units $\mathrm{ft} / \mathrm{min}$
Run No. VT-4

Fan Configuration 2 Fans

Fan Setting Sashes Open

Stack Temp $72.5 \quad \operatorname{deg} \mathrm{F}$

Start/End Time $0915 / 1055$

Center $2 / 3$ from

Points in Center $2 / 3$ 4.01 to: 39.74

Pitot Correction: 0.84

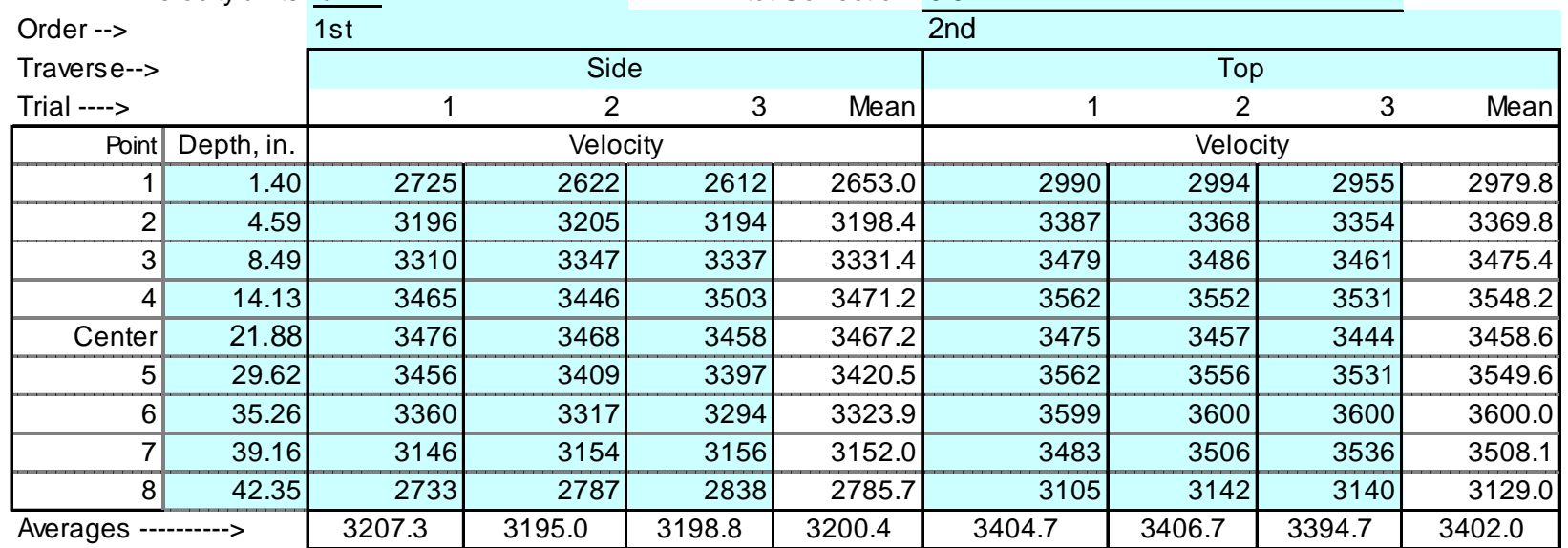

\begin{tabular}{|lrr|lrrr|}
\hline All & $\underline{\mathrm{ft} / \mathrm{min}}$ & Dev. from mean & Center 2/3 & Side & Top & All \\
Mean & 3301.2 & & Mean & 3337.8 & 3501.4 & 3419.6 \\
Min Point & 2653.0 & $-19.6 \%$ & Std. Dev. & 126.2 & 75.4 & 131.1 \\
Max Point & 3600.0 & $9.1 \%$ & COV as \% & 3.8 & 2.2 & $\mathbf{3 . 8}$ \\
\hline
\end{tabular}

Flow w/o C-Pt $34252 \mathrm{acfm}$ $3281 \mathrm{fpm}$

Vel Avg w/o C-Pt

\begin{tabular}{|c|c|}
\hline Start & Finish \\
\hline 72 & 73 \\
\hline N.A. & N.A. \\
\hline 55 & 58 \\
\hline 2.40 & 2.00 \\
\hline 1001 & 997 \\
\hline 1003 & 999 \\
\hline $48 \%$ & $39 \%$ \\
\hline
\end{tabular}

Stack temp

Equipment temp

Ambient temp

Stack static

Ambient pressure Total Stack pressure Ambient humidity

\begin{tabular}{l} 
Instuments Used: \\
Fisher Scientific \\
\hline Zephyr It+
\end{tabular}

\begin{tabular}{llc}
\hline Zephyr II+ & SN 80355 & 9/18/2010 \\
\hline TSI Velocicalc & SN 305039 & 6/23/2010 \\
\hline Dwyer Pitot Tube & PN 1605-72 A304 & Cert. of Conf.
\end{tabular}

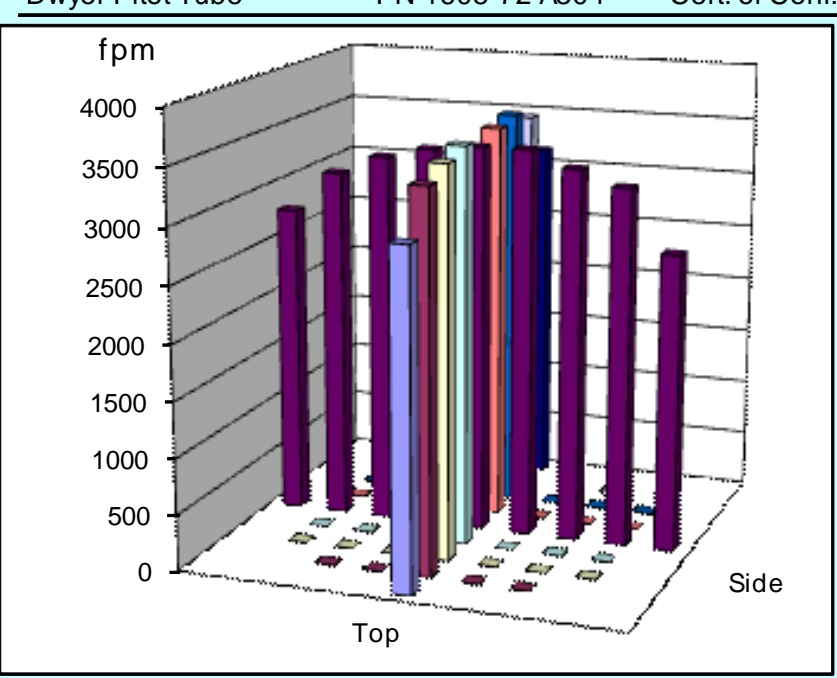

Notes: $\quad$ Stack exit cone has been permanently removed.

\begin{tabular}{ll}
\hline \multicolumn{2}{c|}{ RAES Reading, scfm } \\
\hline Start $\quad 32,100$ \\
\hline End $\quad 32,200$ \\
\hline \\
\hline
\end{tabular}




\section{VELOCITY TRAVERSE DATA FORM}

Site EP-3430-01-S

Date $\mathbf{5 / 2 0 / 1 0}$

Testers JAG, JEF

Stack Dia.

Stack X-Area 1503.3

Test Port nearest probe

Distance to disturbance $53.5 \mathrm{ft}$

Velocity units $\mathrm{ft} / \mathrm{min}$
Run No. VT-5

Fan Configuration 2 Fans

Fan Setting Sashes Open

Stack Temp $73.5 \quad \operatorname{deg} F$

Start/End Time $1100 / 1220$

Center $2 / 3$ from

Points in Center $2 / 3$

4.01 to: 39.74

Pitot Correction: 0.84

\begin{tabular}{|c|c|}
\hline $\begin{array}{l}\text { Order --> } \\
\text { Traverse--> } \\
\text { Trial ----> }\end{array}$ & \\
\hline Point & Depth, in \\
\hline 1 & 1.4 \\
\hline 2 & 4.5 \\
\hline 3 & 8.4 \\
\hline 4 & 14.1 \\
\hline Center & 21.8 \\
\hline 5 & 29.6 \\
\hline 6 & 35.2 \\
\hline 7 & 39.1 \\
\hline 8 & 42. \\
\hline
\end{tabular}

$1 \mathrm{st}$

2nd

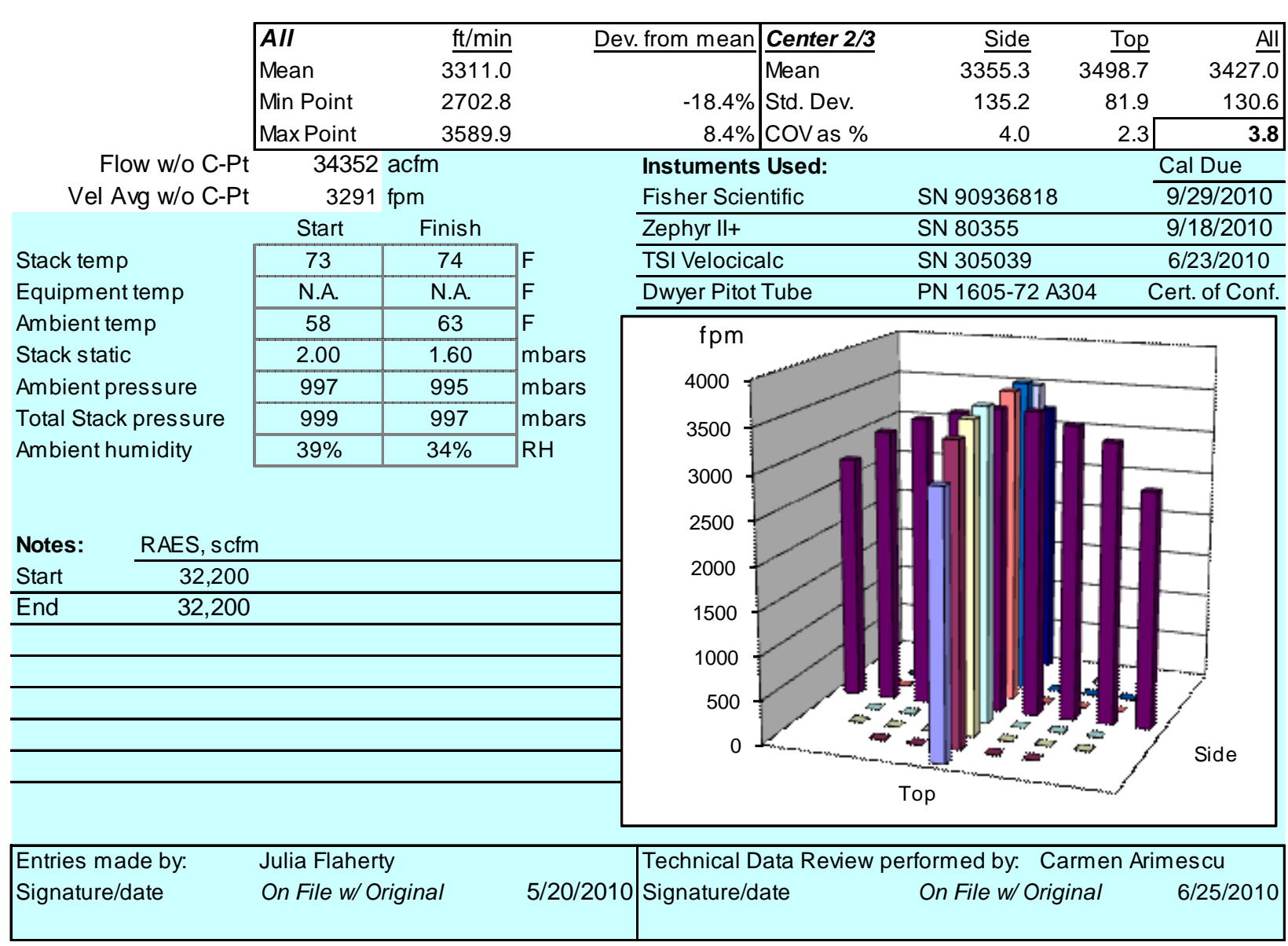




\section{VELOCITY TRAVERSE DATA FORM}

Site EP-3430-01-S

Date $\mathbf{5 / 2 1 / 1 0}$

Testers JAG, JEF

Stack Dia.

Stack X-Area

43.75 in.

Test Port nearest probe

Distance to disturbance $53.5 \mathrm{ft}$

Velocity units $\mathrm{ft} / \mathrm{min}$

Order -->

Traverse-->

Trial ---->

\begin{tabular}{|r|r|}
\hline Point & Depth, in \\
\hline 1 & 1.40 \\
\hline 2 & 4.59 \\
\hline 3 & 8.49 \\
\hline 4 & 14.13 \\
\hline Center & 21.88 \\
\hline 5 & 29.62 \\
\hline 6 & 35.26 \\
\hline 7 & 39.16 \\
\hline 8 & 42.35 \\
\hline Averages -------->
\end{tabular}

2nd
Run No. VT-6

Fan Configuration 2 Fans

Fan Setting Sashes Closed

Stack Temp

Start/End Time $0825 / 0950$

Center $2 / 3$ from

Points in Center 2/3

4.01 to: 39.74

Pitot Corection: 0.84 2

$1 \mathrm{st}$

$\begin{array}{cccc} & & \text { Top } \\ & \text { Mean } & 1 & 2\end{array}$

\begin{tabular}{|c|c|c|c|c|c|c|c|}
\hline 1 & 2 & 3 & Mean & 1 & 2 & 3 & Mean \\
\hline \multicolumn{4}{|c|}{ Velocity } & \multicolumn{4}{|c|}{ Velocity } \\
\hline 1960 & 1929 & 1980 & 1956.1 & 2094 & 2117 & 2130 & 2113.7 \\
\hline 2336 & 2296 & 2298 & 2310.0 & 2439 & 2434 & 2428 & 2433.8 \\
\hline 2420 & 2419 & 2414 & 2417.8 & 2495 & 2524 & 2546 & 2521.7 \\
\hline 2491 & 2497 & 2486 & 2491.7 & 2568 & 2552 & 2596 & 2572.1 \\
\hline 2517 & 2513 & 2507 & 2512.7 & 2516 & 2474 & 2505 & 2498.2 \\
\hline 2536 & 2525 & 2532 & 2530.9 & 2565 & 2565 & 2571 & 2567.0 \\
\hline 2487 & 2460 & 2439 & 2462.0 & 2497 & 2502 & 2521 & 2506.8 \\
\hline 2350 & 2341 & 2334 & 2341.9 & 2375 & 2391 & 2405 & 2390.1 \\
\hline 2026 & 2009 & 2032 & 2022.4 & 2113 & 2133 & 2105 & 2117.1 \\
\hline 2347.1 & 2332.2 & 2335.9 & 2338.4 & 2406.9 & 2410.1 & 2423.1 & 2413.4 \\
\hline
\end{tabular}

\begin{tabular}{|lrr|lrrr|}
\hline All & ft/min & Dev. from mean & Center 2/3 & Side & Top & All \\
Mean & 2375.9 & & Mean & 2438.2 & 2498.5 & 2468.3 \\
Min Point & 1956.1 & $-17.7 \%$ & Std. Dev. & 85.3 & 66.7 & 80.0 \\
Max Point & 2572.1 & $8.3 \%$ & COV as \% & 3.5 & 2.7 & $\mathbf{3 . 2}$ \\
\hline
\end{tabular}

Flow w/o C-Pt $24634 \mathrm{acfm}$ Vel Avg w/o C-Pt 2360 fpm

\begin{tabular}{|c|c|c|}
\hline \multirow{3}{*}{$\begin{array}{l}\text { Stack temp } \\
\text { Equipment temp }\end{array}$} & Start & Finish \\
\hline & 60 & 65 \\
\hline & N.A. & N.A. \\
\hline Ambient temp & 63 & 60 \\
\hline Stack static & 0.70 & 0.80 \\
\hline Ambient pressure & 1008 & 1000 \\
\hline Total Stack pressure & 1009 & 1001 \\
\hline Ambient humidity & $34 \%$ & $41 \%$ \\
\hline
\end{tabular}

\begin{tabular}{lll} 
Instuments Used: & & Cal Due \\
\cline { 3 - 3 } Fisher Scientific & SN 90936818 & 9/29/2010 \\
\hline Zephyr II+ & SN 80355 & 9/18/2010 \\
\hline TSI Velocicalc & SN 305039 & 6/23/2010 \\
\hline Dwyer Pitot Tube & PN 1605-72 A304 & Cert. of Conf. \\
\hline
\end{tabular}

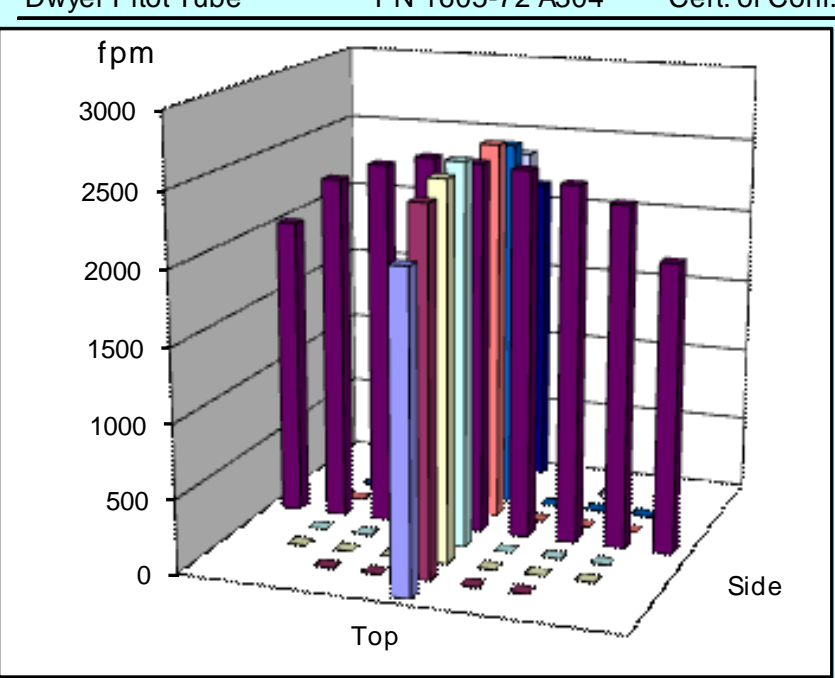

Notes: $\quad$ RAES, scfm

\begin{tabular}{ll}
\cline { 2 - 2 } Start & 23,500 \\
\hline End & 23,600
\end{tabular}

\begin{tabular}{l}
\hline \\
\hline Matthew measured $53 \mathrm{ft} 10$ in from test ports to \\
\hline disturbance.
\end{tabular}

Entries made by: Signature/date

\begin{abstract}
John Glissmeyer
On File w/ Original
\end{abstract}

Technical Data Review performed by: Carmen Arimescu 5/21/2010 Signature/date
On File w/ Original

$6 / 25 / 2010$ 


\section{VELOCITY TRAVERSE DATA FORM}

Site EP-3430-01-S

Date $\mathbf{5 / 2 1 / 1 0}$

Testers JAG, JEF

Stack Dia.

Stack X-Area 1503.3

Test Port nearest probe

Distance to disturbance $53.5 \mathrm{ft}$

Velocity units $\mathrm{ft} / \mathrm{min}$
Run No. VT-7

Fan Configuration 1 Fan (\#2 on - near fan)

Fan Setting $\sim 60 \%$, Sashes Closed

Stack Temp $66.5 \quad \operatorname{deg} F$

Start/End Time 1025/1145

Center $2 / 3$ from

Points in Center $2 / 3$

4.01 to: 39.74

Pitot Correction: 0.84

\begin{tabular}{|c|c|}
\hline $\begin{array}{l}\text { Order --> } \\
\text { Traverse--> } \\
\text { Trial ----> }\end{array}$ & \\
\hline Point & Depth, in. \\
\hline 1 & 1.40 \\
\hline 2 & 4.59 \\
\hline 3 & 8.49 \\
\hline 4 & 14.13 \\
\hline Center & 21.88 \\
\hline 5 & 29.6 \\
\hline 6 & 35.2 \\
\hline 7 & 39.16 \\
\hline 8 & 42.3 \\
\hline
\end{tabular}

$1 \mathrm{st}$

2nd

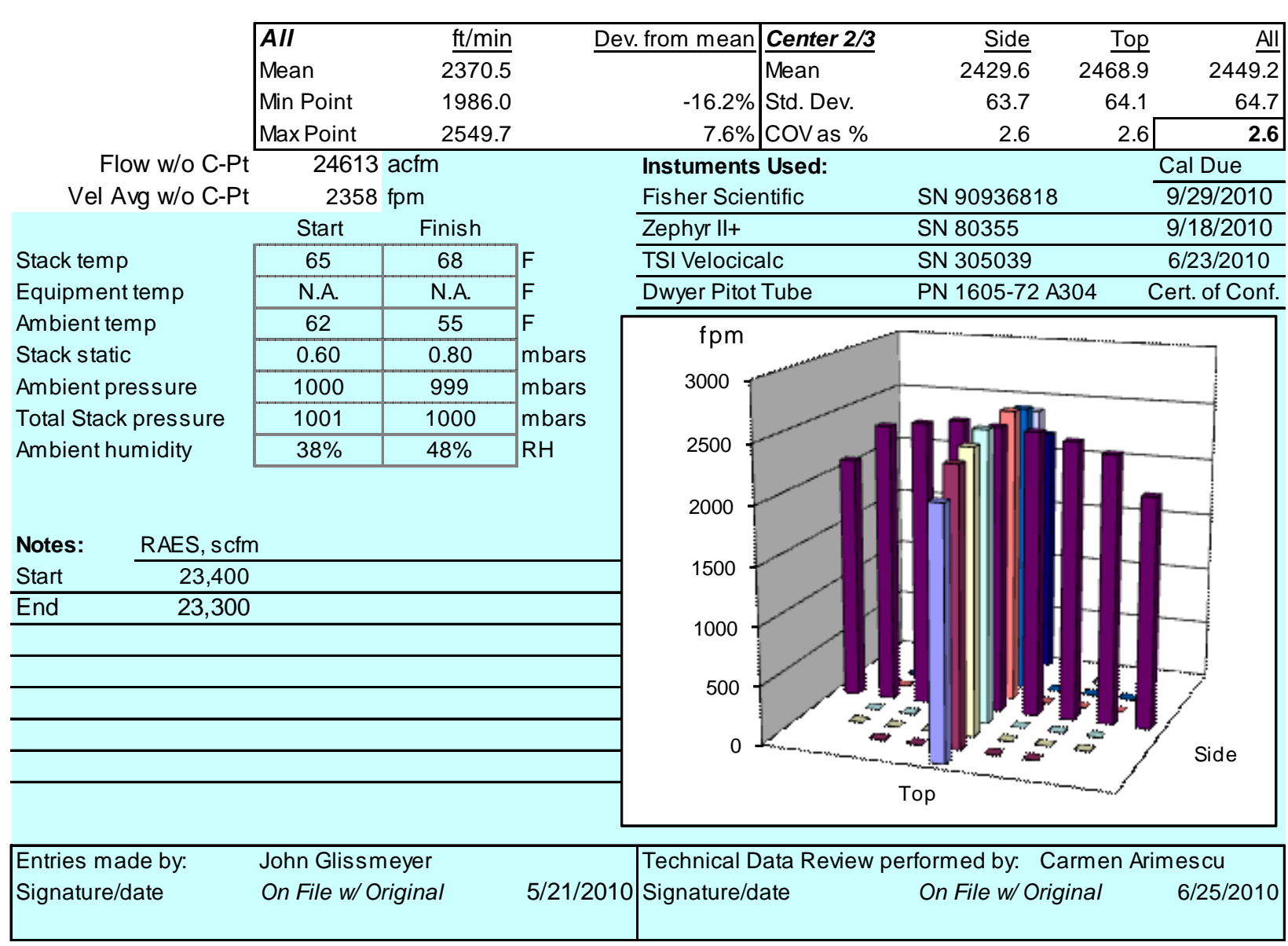


Appendix B

Applicable Qualification Results from the Model Stack 


\section{Appendix B: Applicable Qualification Results from the Model Stack}

These data are extracted from the report by Glissmeyer and Droppo (2007).

Table B.1 lists the gas-tracer uniformity tests conducted on the scale model with the dampers installed at the fan outlets. Only the data for Test Ports 2 and 3 are shown. The model test port 3 was about the same number of duct diameters to the nearest upstream disturbance, whereas the model test port 2 was about 5 duct diameters closer to the nearest upstream disturbance than the test ports on the 3430 Building Filtered Exhaust Stack.

The $\% \mathrm{COV}$ was calculated for the measured gas concentration at the points in the center two-thirds area of the 3430 Building Filtered Exhaust Stack. The percent deviation from the mean concentration was also calculated for any point in the measurement grid.

Table B.1. Summarized Results of Gas-Tracer Uniformity Tests with Dampers

\begin{tabular}{|c|c|c|c|c|c|c|c|c|}
\hline \multicolumn{2}{|c|}{ Injection Port } & \multirow{2}{*}{$\begin{array}{c}\text { Operating } \\
\text { Fans }\end{array}$} & \multirow{2}{*}{$\begin{array}{c}\text { Test } \\
\text { Port }\end{array}$} & \multirow{2}{*}{$\frac{\text { Run No. }}{\text { GT-49 }}$} & \multirow{2}{*}{$\begin{array}{c}\begin{array}{c}\text { Control } \\
\text { Damper } \\
\text { Setting } \\
\text { (degrees) }\end{array} \\
45.0\end{array}$} & \multirow{2}{*}{$\begin{array}{c}\text { Back Flow } \\
\text { Damper } \\
\text { Setting } \\
\text { (degrees) }\end{array}$} & \multirow{2}{*}{$\begin{array}{c}\begin{array}{c}\text { Center } \\
2 / 3 \% \mathrm{COV}\end{array} \\
1.7\end{array}$} & \multirow{2}{*}{$\begin{array}{c}\begin{array}{c}\% \\
\text { Deviation } \\
\text { from Mean }\end{array} \\
4.4\end{array}$} \\
\hline B & Center & & & & & & & \\
\hline B & Center & $A \& B$ & 3 & GT-48 & 45.0 & 45.0 & 1.3 & 2.6 \\
\hline A & Center & A & 2 & GT-38 & 90.0 & 70.0 & 1.3 & 2.6 \\
\hline A & Center & A & 3 & GT-37 & 90.0 & 70.0 & 2.3 & 5.3 \\
\hline A & Center & $A \& B$ & 2 & GT-27 & 90.0 & 70.0 & 7.2 & 13.8 \\
\hline A & Center & A \& B & 3 & GT-34 & 90.0 & 70.0 & 3.2 & 7.9 \\
\hline B & Center & B & 2 & GT-46 & 90.0 & 70.0 & 1.1 & 1.9 \\
\hline B & Center & B & 3 & GT-47 & 90.0 & 70.0 & 1.7 & 2.9 \\
\hline B & Center & $A \& B$ & 2 & GT-52 & 90.0 & 70.0 & 6.3 & 12.3 \\
\hline B & Center & A \& B & 3 & GT-54 & 90.0 & 70.0 & 3.9 & 9.1 \\
\hline A & Far Left & $A \& B$ & 2 & GT-28 & 90.0 & 70.0 & 5.2 & 9.8 \\
\hline A & Far Left & $A \& B$ & 2 & GT-31 & 90.0 & 70.0 & 4.5 & 13.1 \\
\hline A & Far Left & $A \& B$ & 3 & GT-32 & 90.0 & 70.0 & 3.2 & 6.6 \\
\hline A & Far Right & $A \& B$ & 2 & GT-29 & 90.0 & 70.0 & 10.0 & 28.3 \\
\hline A & Far Right & $A \& B$ & 3 & GT-33 & 90.0 & 70.0 & 2.8 & 5.8 \\
\hline A & Near Left & A \& B & 2 & GT-51 & 90.0 & 70.0 & 2.0 & 4.5 \\
\hline A & Near Left & $A \& B$ & 3 & GT-36 & 90.0 & 70.0 & 2.9 & 5.5 \\
\hline A & Near Right & $A \& B$ & 2 & GT-30 & 90.0 & 70.0 & 5.7 & 9.6 \\
\hline A & Near Right & $A \& B$ & 3 & GT-35 & 90.0 & 70.0 & 3.5 & 7.9 \\
\hline
\end{tabular}

Table B.2 lists the particle tracer uniformity results for the model stack. Data are shown for Test Ports 2 and 3. The test ports on the 3430 Building Filtered Exhaust Stack were about 5 duct diameters farther downstream of the duct junction than Test Port 2 on the model, and were at a similar relative position to test port 3 on the model. The last column shows the uniformity results for the combination of operating parameters tested. 
Table B.2. Particle-Tracer Uniformity Tests with Dampers

\begin{tabular}{ccccccc}
\hline $\begin{array}{c}\text { Injection } \\
\text { Port }\end{array}$ & $\begin{array}{c}\text { Operating } \\
\text { Fans }\end{array}$ & Test Port & Run No. & $\begin{array}{c}\text { Control Damper } \\
\text { Setting (degrees) }\end{array}$ & $\begin{array}{c}\text { Back Flow } \\
\text { Damper Setting } \\
\text { (degrees) }\end{array}$ & $\begin{array}{c}\text { Normalized } \\
\% \text { COV }\end{array}$ \\
\hline A & A \& B & 2 & PT-12 & 90 & 70 & 13.75 \\
A & A \& B & 2 & PT-21 & 90 & 70 & 7.41 \\
A & A \& B & 3 & PT-13 & 90 & 70 & 9.72 \\
A & A \& B & 3 & PT-20 & 90 & 70 & 8.12 \\
A & A & 2 & PT-15 & 90 & 70 & 2.46 \\
A & A & 3 & PT-14 & 90 & 70 & 3.73 \\
B & B & 2 & PT-18 & 90 & 70 & 3.02 \\
B & B & 3 & PT-19 & 90 & 70 & 3.61 \\
\hline
\end{tabular}


PNNL-19262, Rev. 1

RPT-STMON-002, Rev. 1

\section{Distribution}

No. of

Copies

ONSITE

9 Pacific Northwest National Laboratory

JA Glissmeyer (3) K3-54

JM Barnett (2) J2-25

JE Flaherty K9-30

JT Hickman J2-09

RJ Steele J2-53

RS Sallee J2-19

Distr. 1 



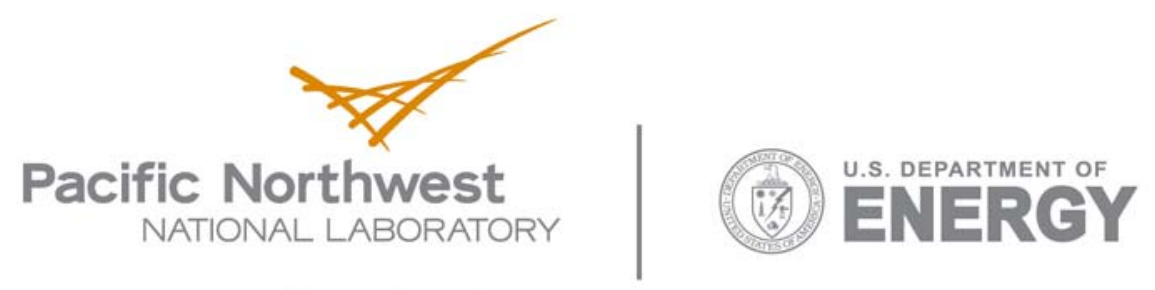

902 Battelle Boulevard

P.O. Box 999

Richland, WA 99352

1-888-375-PNNL (7665)

www.pnl.gov 